Review

\title{
Role of Plant Derived Alkaloids and Their Mechanism in Neurodegenerative Disorders
}

\author{
Ghulam Hussain 1,3, Azhar Rasul1,5, Haseeb Anwar3, Nimra Aziz ${ }^{3}$, Aroona Razzaq33, Wei Wei1,2, \\ Muhammad $\mathrm{Ali}^{4}$, Jiang $\mathrm{Li}^{2 \bowtie}$, Xiaomeng $\mathrm{Li}^{1}$ \\ 1. The Key Laboratory of Molecular Epigenetics of MOE, Institute of Genetics and Cytology, Northeast Normal University, Changchun 130024, China \\ 2. Dental Hospital, Jilin University, Changchun 130021, China \\ 3. Department of Physiology, Faculty of Life Sciences, Government College University, Faisalabad, 38000 Pakistan \\ 4. Department of Zoology, Faculty of Life Sciences, Government College University, Faisalabad, 38000 Pakistan \\ 5. Chemical Biology Research Group, RIKEN Center for Sustainable Resource Science. 2-1 Hirosawa, Wako, Saitama 351-0198 Japan
}

$\triangle$ Corresponding authors: Professor Xiaomeng Li, The Key Laboratory of Molecular Epigenetics of Ministry of Education, Institute of Genetics and Cytology, Northeast Normal University, 5268 People's Street, Changchun, Jilin 130024, P.R. China. E-mail: lixm441@nenu.edu.cn Tel: +86 186 86531019; Fax: +86 431 85579335 or Professor Jiang Li, Department of Prosthodontics, Dental Hospital, Jilin University, 1500 Tsinghua Road, Changchun, Jilin 130021, P.R. China. E-mail: ljiang@jlu.edu.cn

(C) Ivyspring International Publisher. This is an open access article distributed under the terms of the Creative Commons Attribution (CC BY-NC) license (https://creativecommons.org/licenses/by-nc/4.0/). See http://ivyspring.com/terms for full terms and conditions.

Received: 2017.10.09; Accepted: 2017.12.18; Published: 2018.03.09

\begin{abstract}
Neurodegenerative diseases are conventionally demarcated as disorders with selective loss of neurons. Conventional as well as newer molecules have been tested but they offer just symptomatic advantages along with abundant side effects. The discovery of more compelling molecules that can halt the pathology of these diseases will be considered as a miracle of present time. Several synthetic compounds are available but they may cause several other health issues. Therefore, natural molecules from the plants and other sources are being discovered to replace available medicines. In conventional medicational therapies, several plants have been reported to bestow remedial effects. Phytochemicals from medicinal plants can provide a better and safer alternative to synthetic molecules. Many phytochemicals have been identified that cure the human body from a number of diseases. The present article reviews the potential efficacy of plant-derived alkaloids, which possess potential therapeutic effects against several NDDs including Alzheimer's disease (AD), Huntington disease (HD), Parkinson's disease (PD), Epilepsy, Schizophrenia, and stroke. Alkaloids include isoquinoline, indole, pyrroloindole, oxindole, piperidine, pyridine, aporphine, vinca, $\beta$-carboline, methylxanthene, lycopodium, and erythrine byproducts. Alkaloids constitute positive roles in ameliorating pathophysiology of these illnesses by functioning as muscarinic and adenosine receptors agonists, anti-oxidant, anti-amyloid and MAO inhibitors, acetylcholinestrase and butyrylcholinesterase inhibitor, inhibitor of $\alpha$-synuclein aggregation, dopaminergic and nicotine agonist, and NMDA antagonist.
\end{abstract}

Key words: Neurodegenerative diseases, Phytochemicals, Plant derived alkaloids, acetylcholinestrase, butyrylcholinesterase, monoamine oxidase.

\section{Introduction}

Neurodegenerative diseases (NDDs) are the disorders of nervous system and are conventionally demarcated as a selective loss of neurons. Studies demonstrated that physicochemical properties of proteins are altered that cause deposition of these proteins in the human brain leading to neuronal degeneration [1]. NDDs are cureless till date and are significantly increasing the mortality and morbidity rate in the developed countries and same scenario is expected in the developing countries as the information pile up $[2,3]$. Neuropsychiatric and neurological disorders like schizophrenia, depression, anxiety, Alzheimer's disease (AD), Parkinson's disease (PD), Huntington's disease (HD), Amyotrophic Lateral Sclerosis (ALS), cerebrovascular impairment, seizure disorders and head injuries are the major health issues along with other systemic disorders like cardiovascular, respiratory, renal, 
gastrointestinal and many others in the $21^{\text {st }}$ century [3]. The available remedies against NDDs are solely based on the management of these diseases but actual treatment is yet to be explored. There are several NDDs with similar symptoms but have different mechanisms of pathogenesis [4-6].

$\mathrm{AD}$ is one of the major NDDs with the progressive deterioration of memory, learning and other cognitive functions and involves the formation of disorientated plaques, neurofibrillary masses that result in an extensive neuronal loss. Beta-amyloid peptide $(A \beta)$ is the foremost element of senile plaques that is mainly involved in the developmental process of $\mathrm{AD}$ [7]. Aggregation of $\mathrm{A} \beta$ leads to neuronal cell death by causing energy reduction, oxidative stress, inflammation and apoptosis [8]. Brain sections with plaques usually demonstrate the decreased figure of synapses as well as the plaques associated neurites are normally scratched, which signifies that $A \beta$ damages neurites and synapses. Whereas acetyl-cholinergic or glutamatergic neurons give the impression as of predominantly affected. Importantly, amyloid precursor protein (APP) outcomes as the creation and accretion of neurotoxic forms of $A \beta$ [9]. $A \beta$ are generated by gamma-secretase-mediated sequential cleavages of APP and $\beta$-secretase (beta-site amyloid precursor protein cleaving enzyme, BACE) [10].

PD involves the dopaminergic neuronal loss in substantia nigra pars compacta (SNpc) and is second most common neurodegenerative disorder. It chiefly results in the tremor, rigidity, bradyphrenia, bradykinesia, postural instability and gait impairment [11-13]. The adult hippocampal dentate gyrus (DG) receives inputs from dopaminergic neurons in SN. So, deterioration of dopaminergic neurons may directly affect adult hippocampal neurogenesis [14]. Lewy bodies (LB) are associated with the pathology of PD and a-synuclein is the chief component of LB which become aggregated in PD [15].

HD is a progressive neurodegenerative disorder and is documented to have the frequency of 5-10 cases per 100,000 globally. It is an inherited disease of autosomal dominant trait [22] which involves neuronal cell death particularly in cerebral cortex and striatum. It mitigates the life expectancy and leads to the disability of the effected subject [16]. HD is characterized by decline in cognitive and motor ability, psychiatric disturbance, chorea, suicide risk and depression which eventually lead to death $[17,18]$. Onset age for HD is typically mid to late stage of life but infrequently juvenile onset is also observed [19]. The gene which encodes for HD is huntingtin (Htt) that has variable length of polyglutamine (polyQ) tract. HD occurs due to CAG repeat expansion in $\mathrm{Htt}$ gene which results in the development mutant $\mathrm{Htt}$ protein with extended polyQ tract greater than $36 \mathrm{Q}$ in the $\mathrm{N}$-terminus of $\mathrm{Htt}$ $[20,21]$.

Stroke results in the abrupt loss in brain functioning because of cerebral blood supply disruption and are the second foremost cause of death. The symptoms usually last for at least for 24 hours or lead to the death [23]. Stroke is an acute neurologic malfunctioning of vascular source with sudden (seconds) or may be at rapid (hours) occurrence of symptoms [24]. Cerebral blood reduction and cerebrovascular diseases are mainly caused by embolism, focal hypoperfusion and thrombosis. At rest brain receives $20 \%$ of the blood, so it is intricately sensitive to ischemia. Even short-lived periods of ischemia to neurons can elicit a multifaceted events that may result in everlasting cerebral mutilation [24].

Almost $45 \%$ of the ischemic strokes are instigated by thrombus in large or small artery, $20 \%$ of strokes are embolic in derivation. When plaques are produced along the injured vessel and intima is abraded, it can results in the formation of thrombosis in intracranial arteries [25]. The injury of the endothelial consents platelets to adhere and aggregate, then coagulation starts, and thrombus progresses at the plaque site. As a result, intracranial and extra cranial systemic blood flow decreases, and function is maintained by collateral system [26]. Studies suggest that during cerebral ischemia there is an activation of NMDA receptor which results in accumulation of ROS resulting in oxidation of vital cellular components. This also amends the signaling pathways which then lead to cellular damage and death [27].

Schizophrenia is a serious psychiatric disorder with symptoms of hallucinations, delusions and disorganized thinking. This is an illness with an unclear cause but the theories have suggested that demyelination of white matter is the etiology of schizophrenia [28]. Some of the morphological brain anomalies perceived in schizophrenia patients includes loss of cortical gray matter [29] the minimized hippocampal volume, the amygdala, temporal, frontal lobes and enlarged ventricular regions [30]. Schizophrenic pathophysiology involve reduced availability of ATP followed by mitochondrial dysfunction diminishing the activity of $\mathrm{Na}+\mathrm{K}+$ ATPase maintaining the membrane potential leading to prolonged depolarization and increasing receptors activity by exuding magnesium from the N-methyl-D-aspartate receptors (NMDAR) [31].

Several approaches have been used to manage the NDDs and most of them exerts positive efficacy by improving health status but none of them has been 
proved as a proper remedy [32]. Plant derived components or phytomedicines such as alkaloids and flavonoids have been used from the ancient times against NDDS. They have been potentially proved as the most effective management and therapeutic agents to minimize the crucial aspects of NDDs such as AD, PD, stroke and schizophrenia [33]. Phytochemicals or the phytomedicines are the bioactive plant compounds found in vegetables, fruits, grains etc. and regular intake of fruits and vegetables can reduce the risks of various diseases that cause neuronal dysfunction. There are several phytochemicals which possess neuroprotective potential and alkaloids are one of the most reliable agent against NDDs [33].

Alkaloids are naturally occurring compounds containing carbon, hydrogen, nitrogen, and usually oxygen and are primarily found in plants, especially in certain flowering plants [34]. A single plant species usually comprises of few kind of alkaloids but numerous families of plants such as Solanaceae (nightshades), Papaveraceae (poppies family), Ranunculaceae (buttercups) and Amaryllidaceae (amaryllis) are predominantly rich in several kinds of alkaloids [35]. Figure 1 illustrates the role of alkaloids in a variety of NDDs.

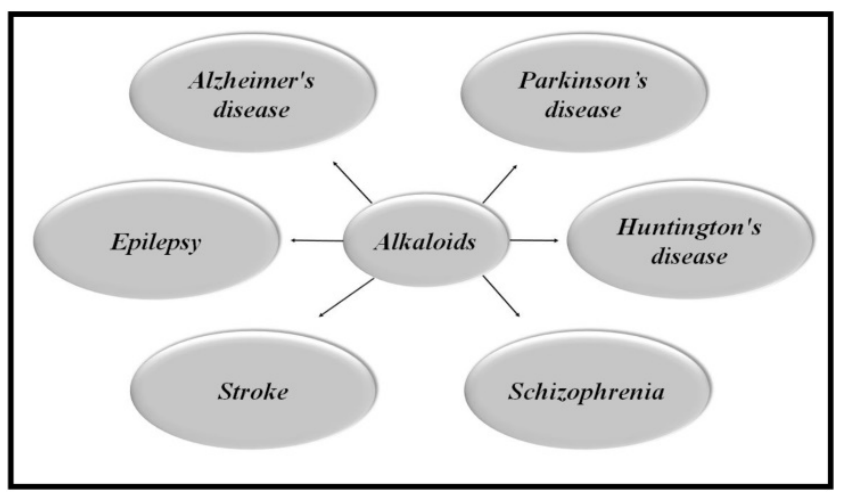

FIGURE I: ALKALOIDS IN NEURODEGENERATIVE DISEASES. Because of the influential and multiple actions of alkaloids, they possess a variety of pharmacological potentials in modern medicine and the effects includes analgesic (e.g., morphine), anti-hyperglycemic (e.g., piperine), anticancer (e.g., berberine), antiarrhythmic (e.g., quinidine), antibacterial (e.g., ciprofloxacin). Some other alkaloids exhibit stimulant effects to CNS (e.g., cocaine, caffeine, and nicotine) as well as psychotropic effects (e.g., psilocin). Although alkaloids have an extensive history and numerous applications but only a few are promoted as active medicine [36]. Alkaloids exert numerous neuro-protective activities in numerous diseases such as epilepsy, psychological disorders, cerebral ischemia, dementia and memory impairment, depression, anxiety, HD, PD, AD and many others [37]. Alkaloids attenuates the development of NDDs through their vast mode of action, i.e., via inhibiting the activity of acetyl-cholinesterase (AChE) enzyme [38], by increasing the level of gamma-aminobutyric acid (GABA) [35], by acting as antagonist of NMDA [39] and many more as described in Fig 2 .

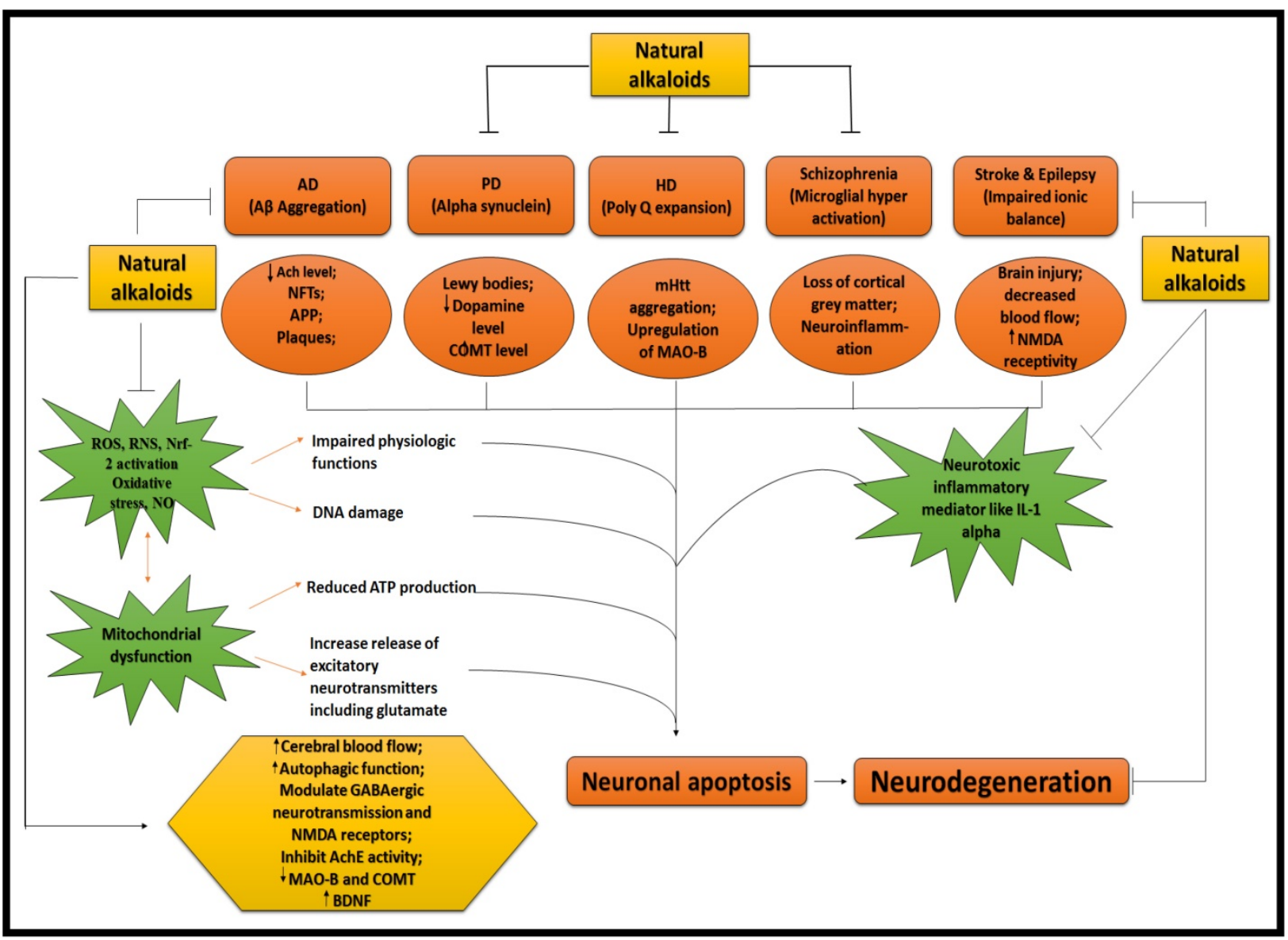

FIGURE 2: NEUROPROTECTIVE EFFICACY OF ALKALOIDS. Ach = Acetylcholine; $\mathbf{A c h E}=$ Acetylcholinestrase; $\mathbf{A P P}=$ Amyoid precursor protein; $\mathbf{C O M T}=$ Catechol-O-methyltransferase; MAO-B = Monoamine oxidase B; NMDA = N-methyl-D-aspartate; IL-1 = Interleukin 1; ROS = Reactive oxygen species; RNS = Reactive nitrogen species; NO = Nitric oxide; Nrf = Nuclear factor erthyroid; BDNF = Brain derived neurotropic factor 
Table 1: Classes of Alkaloids, their source and target neurodegenerative diseases

\begin{tabular}{|c|c|c|c|c|}
\hline Class of alkaloids & Alkaloids & Plants source & Diseases & References \\
\hline \multirow[t]{5}{*}{ Isoquinoline alkaloids } & Berberine & $\begin{array}{l}\text { Hydrastis Canadensis, Coptis } \\
\text { Chinensis, Berberis } \\
\text { aquifolium, Berberis vulgaris, } \\
\text { Berberis aristata }\end{array}$ & AD, PD, HD, and Epilepsy & {$[40-43]$} \\
\hline & Morphine & $\begin{array}{l}\text { Papaver somniferum (opium } \\
\text { poppy) }\end{array}$ & $\mathrm{AD}$ & [35] \\
\hline & Montanine & Hippeastrum vittatum & Epilepsy & [44] \\
\hline & Salsoline & Salsola oppositefolia & $\mathrm{AD}$ & [45] \\
\hline & Galantamine & $\begin{array}{l}\text { Narcissus tazetta, Galanthus } \\
\text { nivalis, Leucojum aestivum }\end{array}$ & $\mathrm{AD}$ & [46] \\
\hline Indole alkaloids & Geissospermine & Geissospermum vellosii & $\mathrm{AD}$ & [33] \\
\hline Pyrroloindole alkaloids & Physostigmine & Physostigma venosum & $\mathrm{AD}, \mathrm{PD}$ & {$[45,47]$} \\
\hline \multirow[t]{2}{*}{ Piperidine alkaloids } & Piperine & $\begin{array}{l}\text { black pepper (Piper nigrum) and } \\
\text { long pepper (Piper longum) }\end{array}$ & AD, PD, Epilepsy & {$[48-51]$} \\
\hline & Lobeline & Lobelia inflate & PD & [52] \\
\hline Aporphine alkaloids & Nantenine & fruit of Nandina domestica & Epilepsy & [53] \\
\hline \multirow[t]{2}{*}{ Pyridine alkaloids } & Nicotine & Nicotiana tobaccum & $\mathrm{AD}$ & {$[28,33,54]$} \\
\hline & Arecoline & Areca catech $u$ nut & Schizophrenia & {$[28,55]$} \\
\hline Methylxanthine derivatives & Caffeine & Coffea arabica & $\mathrm{AD}, \mathrm{PD}$ & {$[33,56]$} \\
\hline Vinca alkaloid & Vinpocetine & Vinca minor & Ischemia and hypoxia & {$[57,58]$} \\
\hline Lycopodium alkaloid & Huperzine A & Huperzia serrate & $\mathrm{AD}$ & {$[59,60]$} \\
\hline Indole $\beta$-carboline & Harmine & Peganum harmala & $\mathrm{AD}$ & {$[33,61]$} \\
\hline Erythrine byproducts & $\begin{array}{l}\text { (+)-erythravine and } \\
(+)-11 \text {-a-hydroxyerythravine }\end{array}$ & Erythrina mulungu & Epilepsy & {$[62,63]$} \\
\hline
\end{tabular}

\section{Classification of alkaloids}

Alkaloids are divided into several classes based on their sources, pharmacokinetics and chemical structures. A variety of pharmacological implications of alkaloids in several NDDs are summarized in Table 1.

Alkaloids are elucidated with their availability within the specific part of different plants and their chemical structure in Fig 3.

\section{Berberine}

Berberine (BBR) belongs to the isoquinoline class of alkaloids with a bitter taste and yellow colour, having medicinal use in Ayurvedic and Chinese medicines for about 3000 years. It can be isolated from several plants including Hydrastis Canadensis (Goldenseal), Berberis vulgaris (barberry), Coptis Chinensis (copies or golden thread) and Berberis aristata (tree turmeric) [7].

BBR has multiple pharmacological effects like anti-inflammatory, anti-hypertensive, anti-oxidant, anti-depressant, anti-cancer, anti-microbial, anti-diarrheal, cholesterol and glucose lowering properties [33]. Studies reported that it is beneficial in a number of neuropsychiatric disorders and NDDs. It produces anxiolytic, antidepressant, anti-amnesic effects and exhibits a positive potential in the treatment of drug addiction [64]. BBR possess therapeutic potential for diseases such as AD, PD, $\mathrm{HD}$, cerebral ischemia and schizophrenia $[7,65]$.

\subsection{Therapeutic efficacy of BBR in AD}

Studies have suggested that BBR may be of clinical significance for $A D$ due to its potential in attenuating the $A \beta$ [40]. As the BACE-1 is the APP cleaving enzyme which initiates the $A \beta$ production [66]. BBR improved the behavioral impairment by preventing the hippocampal neurodegeneration and also reduced the activity of BACE-1 activity [67]. Importantly, it also possesses monoamine oxidase (MAO) inhibiting property [68] as well as AChE inhibiting property as both are involved in the advancement of AD [69]. Recently it has been illustrated in another literature that BBR attenuates the deposition of $A \beta$ plaques and prevent the expression of BACE-1 [70]. 

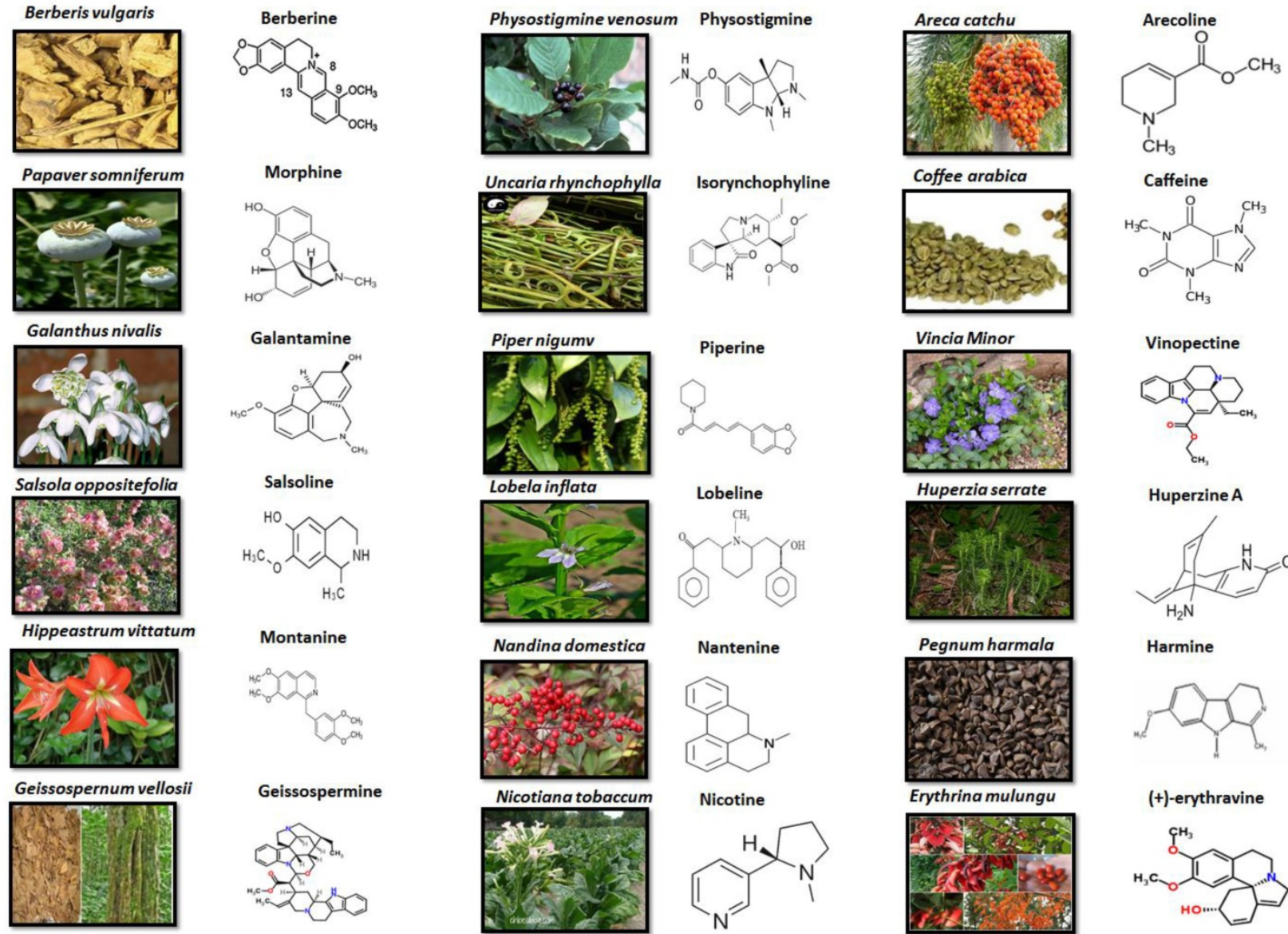

Piperine
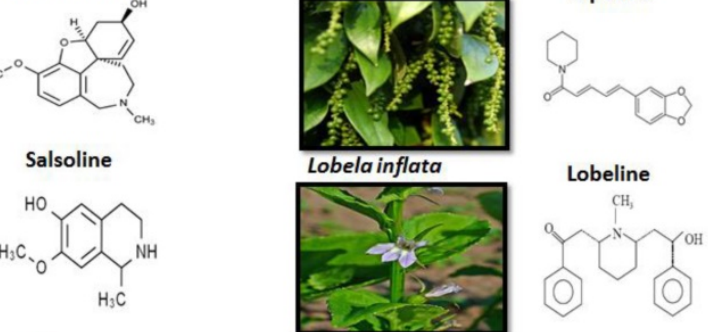

Lobeline

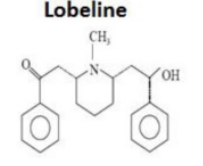

Montanine

Nandina domestica

Nantenine

Vincia Minor
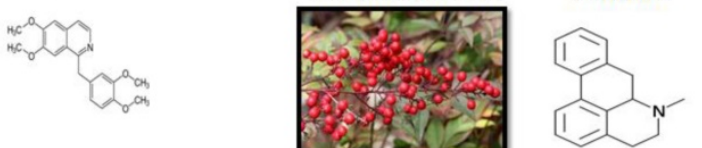

Geissospermine

Nicotiana tobaccum

Nicotine
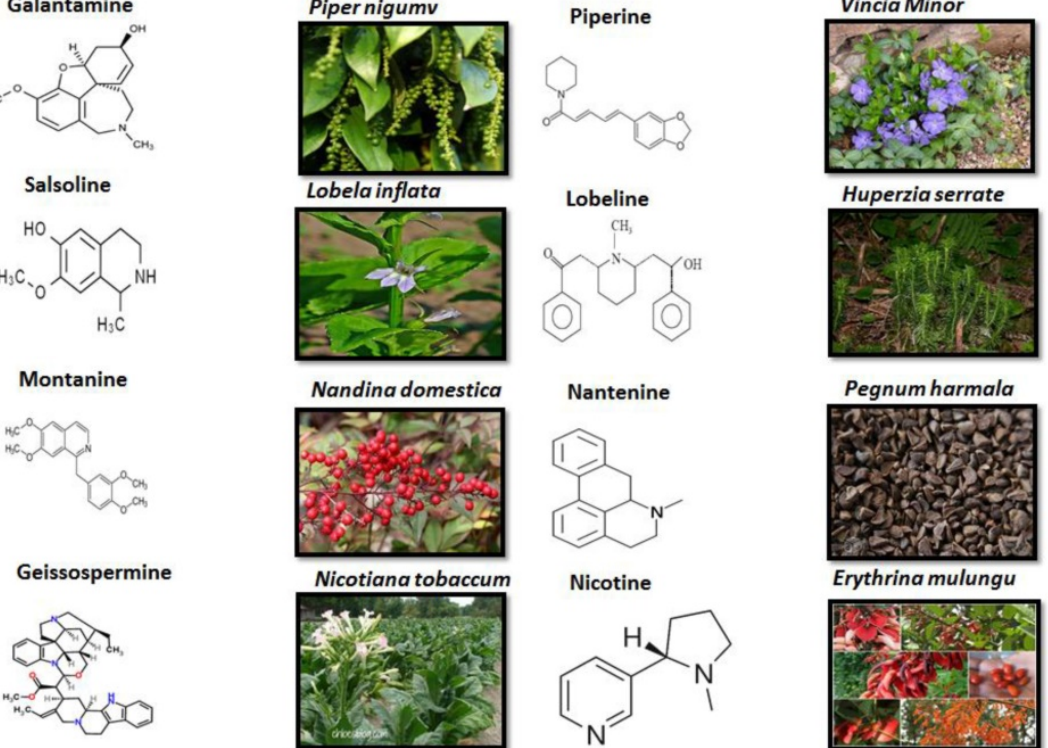

Vinopectine

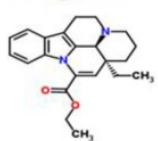

Huperzia serrate

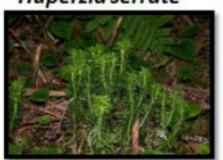

Huperzine A

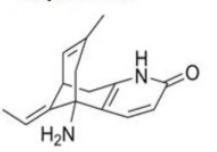

Pegnum harmala

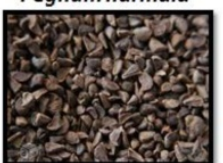

Harmine

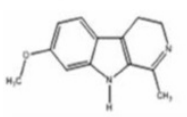

(+)-erythravine
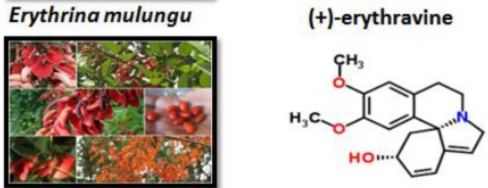

FIGURE 3: PLANT SOURCE AND CHEMICAL STRUCTURE OF ALKALOIDS

\subsection{Therapeutic efficacy of BBR in PD}

BBR enhances the motor stability and synchronization by prevention of neuronal damage of dopaminergic neurons. It also improves short-term memory by inhibiting apoptosis and improving neurogenesis in hippocampal dentate gyrus [71]. It was found that BBR significantly prevented both balance and memory loss in PD and there was reduction in SN dopaminergic neuronal loss and decrease apoptosis in the hippocampus [41].

\subsection{Therapeutic efficacy of BBR in HD}

Currently, HD has no effective medicational therapy, but there are some plant-derived alkaloids, which may have potent effects against this disease. It has been demonstrated that one of the possible therapeutic targets for HD is autophagy [20]. BBR up-regulates the autophagic function [72], which may also beneficial for clearing misfolded proteins in case of HD because misfolding of proteins is hallmark in manifestation of HD [73]. It has also been reported that BBR reduces mutant $\mathrm{Htt}$ deposits and aggregation by activation of autophagic function which improves movement coordination and motor function [42].

\subsection{Therapeutic efficacy of BBR in Epilepsy}

Epilepsy is the neurological disorder, which is characterized by seizures. Although, several antiepileptic drugs (AEDs) are available but they affect the patients with copious side effects and numerous AEDs are seizures resistant. This enhances the interest of researchers to discover phytotherapy to attenuate events of epilepsy [44]. Studies have suggested that extract from Berberis Vulgaris is beneficial in the treatment of epilepsy and convulsions [43]. It has been illustrated that excitotoxicity of NMDAR is linked with pathology of epilepsy. BBR may provide therapeutic potential by averting the activation of excessive extrasynaptic NMDAR [74] and it has been reported that BBR modulates the neurotransmitter system and act as an antagonist of NMDAR [39]. However, more work 
need to be done to explore the potential of BBR as an antagonist of NMDAR.

\section{Toxicity of BBR}

The recommended dose of $\mathrm{BBR}$ in Chinese medicine is $0.2-1.0 \mathrm{~g} /$ day [75]. In some studies, up to $1.5 \mathrm{~g} /$ day has also been recommended in clinical conditions but it may generate adverse effects on gastrointestinal tract (GIT) [76]. There are limited reports about adverse effects of BBR on GIT which include constipation and diarrhea. Neonatal hemolytic jaundice has also been observed due to intake of BBR during pregnancy [77]. Its adverse effects can be reduced if it is administered along with absorption enhancer because it possesses low bioavailability due to its poor intestinal invasion [76].

\section{Morphine}

Morphine is an isoquinoline alkaloid which exerts persuasive narcotic and analgesic effects and is used in the attenuation of moderately serious to extreme pain. Morphine mediates its analgesic activity through the $\mu$-opioid receptor (MOR) [78,79]. Various experimental models revealed that morphine can exhibit advantageous role against neuronal system injuries [80].

\subsection{Therapeutic efficacy of morphine in AD}

Morphine plays a vibrant role in AD treatment via binding to MOR in CNS which increases the levels of GABA in synapse of brain [35] and also provide protection from oxidative stress mediated neurotoxicity [81]. Morphine protects against intracellular $A \beta$ (iA $\beta$ ) venomousness in primary neuronal cultures of rats and human beings. It is capable to reverse the iA $\beta$ induced electrophysiological changes including capacitance and resting membrane potential [80]. Administration of morphine in a dose dependent way reduced the $A \beta$ tempted neurotoxicity via activation of MOR [82].

\section{Toxicity of morphine:}

The significant dose for morphine is less than 200-300 $\mu$ g from a decade ago [83]. The use of morphine is limited due to its side effects such as vomiting and nausea [84]. Administration of morphine during lactation and during and before pregnancy results in pyramidal cell damage as well as impairs spatial memory [85].

\section{Montanine}

Montanine is an isoquinoline alkaloid belonging to Amaryllidaceae family which is isolated from an ornamental plant named Hippeastrum vittatum. It possesses anticonvulsant property [44]. AChE inhibiting property of montanine in a dose dependent manner has also been reported [86]. There are nine Amaryllidaceae species which possess AChE inhibiting properties and montanine is one of them. Montanine is found in bulbs of Hippeastrum vittatum [87].

\subsection{Therapeutic potential of montanine in epilepsy}

Studies have suggested that there is an important role of GABAergic neurotransmission in stress, anxiety, and epilepsy. GABAergic neurotransmission dysfunction has been reported in the patients of anxiety which is associated with epilepsy [88]. It has been reported through experimental investigation that montanine protected against convulsions by modulating the neurotransmitter systems including $\mathrm{GABA}_{\mathrm{A}}$ receptors [44]. It has been suggested that PTZ causes cognitive deficits linked with seizures [89].

\section{Toxicity of montanine}

The adverse health issue which is concerned with montanine is GIT disturbance [90]. Although no latest information has been reported regarding montanine.

\section{Salsoline}

Salsoline is an isoquinoline alkaloid belonging to Chenopodiaceae family [91]. The genus Salsola (Chenopodiaceae) encompasses about 120 species, which are wide- spread bushy plants, particularly in the deep grounds of the moderate and subtropical areas of several countries [91]. It possesses neuroprotective potential against $\mathrm{AD}$ through its cholinesterase inhibitory action [92].

\subsection{Therapeutic efficacy of salsoline in AD}

It has been investigated that cholinergic transmission is reduced in case of $\mathrm{AD}$ which results in loss of cognitive function [93] which can be improved by AChE inhibitors [35]. Salsoline possesses the property of inhibiting the AChE enzyme [45]. It has been demonstrated that the AChE and BuChE inhibitors are beneficial in the treatment of AD [94]. Studies revealed the action of three salsola species for the first time as AChE and BuChE inhibitors. Salsoline is characterized by a selective action against $\mathrm{BuChE}$, thus targeting a novel approach for AD treatment [91]. Hence, more work need to be done in this regard.

\section{Galantamine}

Galantamine is included in isoquinoline class of alkaloids which can be secluded from various plants such as Snowflake (Leucojum aestivum), Snowdrop 
(Galanthus nivalis) and from Daffodil (Narcissus tazetta) as well [35]. Russian pharmacologist for the first time used Snowdrop in the treatment of poliomyelitis. For the treatment of $\mathrm{AD}$, synthetic galantamine was first recognized in 2000 in Sweden. It was successively approved in the United States and the European Union [95].

\subsection{Therapeutic efficacy of galantamine in AD}

It has been suggested that AD is caused by the imbalance in cholinergic system as well as loss of levels of ACh in the brain due to over activation of AChE which might be accountable for the decline in cognition as the neuronal excitability is regulated by ACh [96]. This might generate the hypothesis that AChE inhibitor could ameliorate the drawbacks of AD. It has been reported that galantamine impacts on central cholinergic pathways by inhibiting AChE [69]. As galantamine is the AChE inhibitor (AChEI), thereby it ameliorates the cholinergic neurotransmission by reducing the $\mathrm{ACh}$ breakdown [46]. In another literature, it is demonstrated that it binds to the AChE in the brain which in turn increases the level of $\mathrm{ACh}$ in synaptic cleft by reducing the catabolism of ACh [35]. It has also been reported that it is potentially reversible and selective $\mathrm{AChE}$ inhibitor and several preclinical studies were also carried out to define its pharmacokinetics [33]. Clinical trials have proved that galantamine $(24 \mathrm{mg} / \mathrm{d})$ improved the cognition/perception in the patients of slight AD with no symptoms of hepatotoxicity [97]. Strong suggestions indicated that functional nAChR (particularly the $\alpha 7$ subtype) attenuation/dysfunction in $\mathrm{AD}$ also decreases the learning and memory by blocking of nicotinic agonists $[98,99]$. Galantamine allosterically modulate nAChR activity which potentiates nicotinic neurotransmission and enhance cognition and memory [100]. Furthermore, it exhibits positive stimulation in hippocampal neurogenesis through a7 nicotinic ACh receptors [101]. Many studies have revealed that galantamine inhibits $A \beta$ accumulation and cytotoxicity which is also another hallmark in pathology of AD [102,103]. Galantamine also protects the neurons against oxidative damage by scavenging ROS but more work need to be done in this context [102]. So, all above shows that galantamine may decline the neurodegenerative insults in case of $\mathrm{AD}$ via neurogenesis and neuroprotection.

\section{Toxicity of galantamine}

It has been reported that galantamine at the dose of $26 \mathrm{mg} / \mathrm{kg}$ is very effective in ameliorating the behavioral and cognitive abilities in AD. It also delays the formation of $A \beta$ plaque [104]. But it has also been considered that the long term use of galantamine can significantly attenuate the mortality [105]. The adverse side effects which are linked with the galantamine intake are GIT disturbance, vomiting and nausea $[106,107]$.

\section{Geissospermine}

It is an indole alkaloid belonging to Apocynaceae family which is isolated from Brazilian tree Geissospermum vellosii. It possesses strong anticholinesterase action as well as anti-inflammatory and antinociceptive properties [108]. Aqueous infusions of its bark are frequently used by native societies for countless medicinal determinations. It is medically significant plant and exerts a round figure of medicinal potentials as anti-oxidant [109] as well as antibacterial and antimalarial $[110,111]$.

\subsection{Therapeutic efficacy of GSP in AD}

As it is well-known that AChE leads to advancement of $\mathrm{AD}$. It has been reported that GSP improves cholinergic transmission by its $\mathrm{AChE}$ inhibiting property [33]. One of the investigation demonstrated that docking of the GSP into the dynamic place of AChE displayed particular restricting mode between particular groups of $\mathrm{AChE}$ residues and GSP. Some of the putative ligand/protein collaborations, for example, hydrogen bonds, and hydrophobic interactions were identified in the above complex [112]. Hydrogen holding collaborations were identified with His 440 and Ser200 that could propose the impact of catalytic triad for the AChE inhibiting mechanism through GSP which would help the sketch of new prospective Hurt preventers significant for the management of $\mathrm{AD}$ [112].

\section{Physostigmine}

Physostigmine is a pyrroloindole alkaloid which is also called eserine. It is the first natural alkaloid which was studied as AChE inhibitor [113]. It belongs to the Leguminosae family and isolated from ripe dried seeds of Physostigma venosum. It has the ability to cross blood brain barrier (BBB) [45]. Despite its property to cross the $\mathrm{BBB}$, it has also unveiled narrow therapeutic index, short half- life and peripheral side effects [113].

\subsection{Therapeutic efficacy of physostigmine in AD}

It has been reported that physostigmine improves the cognitive abilities in normal and $A D$ patients [45] and also has the efficacy to inhibit BChE enzyme which is also reported in etiology of AD but inhibition of BChE may cause some adverse effects 
like nausea and vomiting $[113,114]$. Rivastigmine is reported as therapeutically successful synthetic analogue of physostigmine [33] possessing its advantageous clinical efficacy against AD which is recently investigated in patients of AD in Taiwan [94]. Rivastigmine possess dual action, AChE as well as $\mathrm{BuChE}$ inhibiting properties which is useful in alleviating the symptoms of $\mathrm{AD}$ [115].

\subsection{Therapeutic efficacy of physostigmine in PD}

It has been shown that a-synuclein expression increased in PD. There is a great dearth of data regarding antiparkinson effect of physostigmine. However, it was described that phenserine is a physostigmine derivative which possess the efficacy to lower the $a$-synuclein expression in neural cell lines [47]. Recently, no work has been done to explore the therapeutic potential of physostigmine to attenuate the symptoms of PD.

\section{Toxicity of physostigmine}

The dosage of physostigmine as $0.04 \mathrm{mg} / \mathrm{kg}$ considered to be the highest dose with no side effects [116]. There are several side effects which are linked with the use of high dose of piperine including nausea, vomiting, diarrhea, headaches and dizziness [113]. Some other reported adverse effects of physostigmine are enhanced blood pressure and heart rate [117].

\section{Isorhynchophylline}

Isorhynchophylline (IRN) belongs to tetracyclic oxindole class of alkaloids which is extracted from Uncaria rhynchophylla, a chinese herbal medicine which is commonly used in the treatment of neural associated disorders $[118,119]$. It has been reported that it exert positive effects against neurological disorders such as dementia and amnesia [120] as well as ischemia, and epilepsy [35,121]. Japanese neurotrophic medicine called Yokukansan also includes IRN as an important component [122].

\subsection{Therapeutic efficacy of IRN in AD}

Oxidative stress attenuates the body's antioxidant capability and enhances the level of reactive oxygen species (ROS). The brain in particular vulnerable to ROS which is also a main causative factor of abnormal aggregation of $A \beta$ peptides that results in the progression of $\mathrm{AD}$ [123]. It has been reported that a phytochemical, IRN is beneficial in the treatment of $\mathrm{AD}$ because of its neuroprotective efficacy against neurotoxicity caused by $A \beta$ [33] by the suppression of cellular apoptosis induced by mitochondrial pathway and inhibition of oxidative stress $[124,125]$. Experimentation revealed that IRN treatment expressively improves the cognitive shortfalls persuaded in the rats by $A \beta_{25-35}$. Furthermore, IRN down-regulate the levels of the ratio of $\mathrm{Bcl}-2 / \mathrm{Bax}$ of protein by reducing the $A \beta_{25-35}$ tempted neuronal apoptosis in hippocampus [125] as the enhanced level of Bcl-2 promote the survival of altered cells and increase the apoptosis [126].

\subsection{Therapeutic efficacy of IRN in PD}

Alpha-synuclein (a-Syn) masses are the chief constituents of Lewy bodies, which are specific pathological features in PD brain [127]. IRN is an effective agent to treat PD [33] as it degrades the a-synuclein [128] and protects neuronal cells through the autophagy-lysosome pathway [129]. Autophagy referred as self-eating machinery which is used to destroy and reprocess the long lived organelles and proteins for maintenance of cellular homeostasis [130].

\section{Piperine}

Piperine (PIP) is a chief alkaloid found in long pepper (Piper longum) and black pepper (Piper nigrum). It belongs to the Piperaceae family [131]. It has been reported that piperine possesses a diversity of pharmacological effects which include anti-inflammatory, antifungal, insecticidal, antihypertensive, antipyretic, antitumor and analgesic effects as well as possess numerous neuroprotective properties such as antioxidant, antidepressant, anticonvulsant activities [132,133]. The ethanolic extract of Piper longum fruits exert anti-snake venom activities as neurotoxins present in the snake venom cause deadly effects on CNS [134]. Studies have suggested that PIP at all dosage expressively reduced memory impairment. Conversely, it was also found that low dose of PIP is able to increase neuronal density in hippocampus. However, further studies need to be done on its neurogenesis action in hippocampus resulting in memory impairment [50].

\subsection{Therapeutic efficacy of PIP in Epilepsy}

PIP modulates the neurotransmitter systems (serotonin, GABA, Norepinephrine) and delays the tonic-clonic seizures by elevating the cortical and hippocampal serotonin and GABA level [48]. GABA receptors dysfunctions have been suggested to be the underlying cause of epilepsy [135]. Electrophysiological studies revealed the basic mechanism through which PIP serves as an anti-convulsive agent because of its potential to antagonize sodium/calcium channel [48]. Unfortunately, limited data describe the efficacy of PIP as an anti-convulsive agent. Studies 
need to be done to explore its potential therapeutic role for clinical medical use.

\subsection{Therapeutic efficacy of PIP in AD}

PIP promotes the cognitive enhancement via inhibition of $\mathrm{AChE}$ and $\beta$-secretase enzymes. It has been considered that PIP might cross BBB [136]. Administration of Piper nigum L. methanolic extract proved to be beneficial in ameliorating cognition as well as attenuating the oxidative stress in hippocampus of $A \beta_{1-42}$ rat model of $A D$ [49]. Most recently it has been demonstrated that if PIP $(20 \mathrm{mg} / \mathrm{kg})$ is administered in combination with quercetin $(20,40$ and $80 \mathrm{mg} / \mathrm{kg}$ ), it enhances the neuroprotective effect of quercetin as well as attenuates the cognitive deficits and oxidative stress as in case of $\mathrm{AD}$ [137].

\subsection{Therapeutic efficacy of PIP in PD}

MAOs are the mitochondrial bounded enzymes which control the concentration of neurotransmitter such as DA which depicts that they are targets for neurodegenerative disease such as PD [51]. An important enzyme that metabolizes DA is MAO-B. It has been reported that piperine has the ability to inhibit MAO B enzyme which in turn enhance the DA level. PIP also exerts persuasive anti-depressant action which is beneficial in case of PD [50,51]. Studies revealed that PIP has the efficacy to improve the coordination and balance in 6-OHDA induced parkinsonian rats. Furthermore, it has the potency to diminish inflammatory markers, interleukin- $1 \beta$ (IL-1 $\beta$ ) and tumor necrosis factor- $\alpha$ (TNF- $\alpha$ ) in Parkinson's rats which are 6-OHDA-induced. [138].

\section{Toxicity of PIP}

It has been reported that $330 \mathrm{mg} / \mathrm{kg}$ and 514 $\mathrm{mg} / \mathrm{kg}$ are lethal doses of piperine in mice and rats respectively. $100 \mathrm{mg} / \mathrm{kg}$ dose of piperine for 7 days is suggested to be non-toxic [139].

\section{Lobeline}

Lobeline is a piperidine alkaloid isolated from Lobelia inflata and exhibits neuroprotective effects [33]. It is a lipophilic alkaloidal component of Indian tobacco [140].

\subsection{Therapeutic efficacy of lobeline in PD}

Lobeline protects dopaminergic neurons against 1-methyl-4-phenyl-1,2,3,6-tetrahydropyridine (MPTP) which decreases nigral DA [140]. It motivates the DA reverse transportation from synaptic vesicles and inhibits the uptake of DA into synaptic vesicles through the vesicular monoamine transporter 2 communication with it [52].

\section{Toxicity of lobeline}

Although the lobeline exerts neuroprotective effects but it also exerts numerous adverse effects at high doses including nausea, bradycardia, tingling and oral numbness [141].

\section{Nantenine}

Nantenine is an aporphine alkaloid which was first extracted from the Nandina domestica fruit [142]. Nantenine exerts sedative and anticonvulsant effects [53].

\subsection{Therapeutic efficacy of nantenine in Epilepsy}

Calcium signaling causes hyper-excitability by calcium influx which modulate the neuronal activity [143]. Nantenine is effective in epilepsy due to its ability to compansate neuronal hyper-excitability by decreasing calcium influx into the cell $[44,144]$.

\section{Nicotine}

Nicotine is a pyridine alkaloid belonging to Solanaceae family and majorly found in Nicotiana tobaccum. It exhibits extensive pharmacological properties in central nervous system (CNS) as well as the peripheral nervous systems (PNS) mediated by the stimulation of nicotinic acetylcholine receptors (nAChRs) [145]. Nicotine along with few of its derivatives is able to improve dopaminergic neuronal survival as well as synaptic plasticity. Moreover, It reduces neuroinflammation and oxidative stress to decrease the level of pathological condition [146]. Cigarette smoking and tobacco usage have been reported to lower the prevalence of PD and AD [33].

\subsection{Therapeutic efficacy of nicotine in AD}

$\mathrm{AD}$ involves the reduction of cholinergic neurons and high affinity nAChR. Glutamate and several other excitatory amino acids induced neurotoxicity have been also associated with progression of AD [147]. Nicotine elucidates its potential efficacy in promoting the neuroprotection in AD by significantly up regulating the a4 and $a 7$ $n A C h R s$ level [148]. It has been stated as to constrain the formation of $A \beta$-peptide by binding to a-helical structure and also improve the memory and learning mediated via neuropeptide Y (NPY1) receptors [33]. An earlier study on animal model showed that nicotine is able to diminish $\mathrm{AD}$ pathology through one of its chief metabolite named as cotinine [149]. Cotinine expresses its possessions as an alternative of nicotine and exerts potential advantageous properties against pathological mechanism of AD. Furthermore, it averts memory loss in a mouse model of AD by preventing the $\mathrm{A} \beta$ peptides accumulation [54]. 


\section{Toxicity of nicotine}

Despite the potential neuroprotective efficacy in NDDs, nicotine also portrays several toxicological effects [150]. According to the standard data base and safety sheets its lethal dose is $30-60 \mathrm{mg}$ for adults whereas values determined in laboratory animals ranges as $50 \mathrm{mg} / \mathrm{kg}$ in rats and $3.3 \mathrm{mg} / \mathrm{kg}$ in mice [151]. Nicotine exerts its toxic effects through mitochondrial membrane disruption as well as by inducing the production of ROS. Furthermore, it causes the ER stress, which in turn leads to the protein degradation by activating the caspase- 3 activity and finally induces the apoptosis [152].

\section{Arecoline}

Arecoline is a pyridine alkaloid belonging to the family Arecaceae and chiefly found in the fruit of the palm tree Areca catechu L [55]. It has been reported to use as masticatory throughout different parts of Southeast Asia and Indian subcontinent due to its potential therapeutic efficacy [153]. It directly stimulates the cholinergic activity and also elucidates the potential stimulation of CNS by binding to the M2 muscarinic receptors [154]. Several scientific studies have been conducted on Areca nut which indicates its several pharmacological effects like antiinflammatory, analgesic, and antioxidant effects and anti-schizophrenic [155]. Communally, arecoline is a potential agent for treating some CNS disorders due to its efficacy to cross BBB [55].

\subsection{Therapeutic efficacy of arecoline in schizophrenia}

It has been proposed that Oligodendrocytes (OLs) majorly play a significant role in the schizophrenia pathogenesis [156]. Arecoline is reported as a partial agonist of acetylcholine muscarinic receptor which is assumed to exert favorable effects against the schizophrenic symptoms [157]. Arecoline possess its efficacy against schizophrenia by directly targeting the OLs and also prevents the demyelination of white matter. It enhances the social and cognitive activity as well as protects the myelin damage in cortex by facilitating oligodendrocyte precursor cells (OPC) differentiation through dephosphorylating the activated protein kinase AMPKa [28]. Five subtypes (M1-M5) of muscarinic receptor are widely distributed in the CNS which are chiefly involved in a vast variety of functions including nociception, cognition and movement regulation [158]. Some of the earlier studies reported that a significant decrease of M1 and M4 receptors expression in schizophrenic patients with in various regions of brain such as hippocampus [159], prefrontal cortices [160], anterior and posterior cingulate cortex and superior temporal gyrus [161]. Arecoline exerts its potential efficacy against schizophrenia by promoting the body excitability through muscarinic receptors (M receptors) stimulation as well as expand memory and learning abilities [55].

\section{Toxicity of Arecoline}

As it is comprehensively mentioned that arecoline exerts potential benefits in NDDs. Minimum lethal dose of arecoline in animal models of horses, dogs and mice has been accounted as 1.4, 5 and 100 $\mathrm{mg} / \mathrm{kg}$ respectively [162]. It also exerts inflammatory response at the dose of $0.1 \mathrm{mM}$ by producing and releasing the cytokines including prostaglandin E2 and IL-6 [153]. In an experimental study at mature mice model it tends to facilitates the production of ROS at the intra peritoneal dose of $10 \mathrm{mg} / \mathrm{kg}$ [163]. Furthermore, it also exerts cytotoxic effects in neuronal, myoblasts and endothelial cells at the dose of $50 \mu \mathrm{M}, 40 \mu \mathrm{M}$, and $111 \mu \mathrm{g} / \mathrm{mL}$ in vitro $[164,165]$.

\section{Caffeine}

Caffeine is a methylxanthine derivative which is isolated from coffea arabica plant and has been extensively consumed as psychoactive substance, being primarily disbursed in soft drinks, tea and coffee [33]. Its brain stimulation activity primarily involved increased cortical activity, metabolism of cerebral energy, extracellular levels of acetylcholine which communally results in enhanced alertness [166]. A study on animal model revealed that it possesses the ability to reverse the neurotoxicity by acting as antagonist of adenosine receptor [56]. Furthermore, it may able to stimulate the behavioral functions like vigilance, attention, mood, and arousal. Caffeine also exhibits anti-oxidative and anti-inflammatory effects [35]. One of the recent studies reports that coffee consumption reduces the risk of $\mathrm{AD}$ and PD development [33].

\subsection{Therapeutic efficacy of caffeine in AD}

Mutation in presenilins 1 and 2 encoding genes causes alteration in the activity of $\gamma$-secretase and produce $A \beta 42$ isoform in case of $A D$ [147]. Caffeine reduced the $A \beta$ deposition in cortex and hippocampus and suppresses the level of presinilin-1 (PS1), $\beta$ - secretase [167]. As the Caffeine exerts a potential efficacy to act as antagonist of adenosine receptor, thus it potentially reduces neurotoxicity in trial models of AD [56]. Normally microtubules are stabilized by the association of an axonal protein named as tau, whereas misfolding, aggregation as well as abnormal phosphorylation of tau leads to neuronal cell death via the formation of 
neurofibrillary tangle [168]. Caffeine exerts expressive efficacy to reduce tau phosphorylation in hippocampus and the corresponding proteolytic tau fragments [169]. It also protects the basal forebrain neurons and cerebellar granule neurons from neurotoxicity triggered by $A \beta$ [168]. Daily consumption of caffeine at the dose of $300-400 \mathrm{mg}$ [170] in tea, coffee and soft drinks have been reported to reduce cognitive impairment as well as the risk of AD development because of its psycho-stimulant possessions [171].

\subsection{Therapeutic efficacy of caffeine in PD}

Adenosine $\mathrm{A}_{2}$ receptor regulation has been concerned with the modulation of the pro-inflammatory or anti-inflammatory responses and is able to attenuate the locomotor dysfunction as well as tissue damage. Excitotoxicity induced neuronal death can be attenuated by blocking the $A_{2}$ receptor pharmacologically. Caffeine portrays its activity as adenosine A2 receptor antagonist which results in enhanced loco motor activity in Parkinsonism [56]. An augmented number of activated microglial cells had constantly been described in neuro-inflammatory development of PD. The activated microglial cells portray a deleterious influence on dopaminergic neurons [172]. Caffeine has been stated to hold an ability of influencing dopaminergic neurotransmission as well as to attenuate neuronal cell death. Furthermore, it mediates dopamine receptor arbitrated behavioral responses, such as cognitive and locomotion functions [173]. It directs the down-regulation of adenosine A2 receptors to counter the suppressive effect of adenosine on brain dopaminergic transmission [174]. Hence it is stated that caffeine attenuates the pathological progressions of Parkinsonism via different mode of actions as mentioned earlier.

\section{Vinpocetine}

Vinpocetine is an alkaloid which is extracted from Vinca minor or commonly known as periwinkle plant [175]. It was originally marketed under the trade name as Cavinton in 1978. Since the time, it has widely been used in the improvement of cognitive impairment in the conditions such as $\mathrm{AD}$, stroke, memory disturbance as well as in the treatment of cerebrovascular disorders [176]. Its biological activities include an increase in blood flow, glucose uptake, improvement in microcirculation, reduction in platelets accumulation [177]. Its advantageous clinical outcome is based on its varied range of action such as anti-inflammatory, anti-oxidant, vasodilation and neuro-protective agent via different underlying mechanisms.one of the underlying mechanism of its vasodilation activity involves the enhanced glucose and oxygen uptake as well as elevated production of neuronal ATP [177].

\subsection{Therapeutic efficacy of Vinpocetine in Ischemia and hypoxia}

After ischemic stroke restoration of blood flow to the brain prevents additional widespread impairment but can lead to the reperfusion injury. The inflammatory reaction accounts for one of the many features involved in cerebral ischemia reperfusion damage [57]. A protein complex known as necrosis factor-kappa Bis (NF-kB) is majorly involved in the continuation and amplification (cascade outcome) of the inflammatory response [178]. Activated NF-kB stimulate other proteins like RNA polymerase as well as co-activators to enhance transcription of mRNA. Thus Vinpocetine efficiently exerts a potential to induce a wide range of cell factors like chemokine's and cytokines leading to the further activation of $\mathrm{NF}-\mathrm{kB}$ [179]. It halts the inflammatory response via defeating the NF- $\mathrm{kB}$ movement from the cytoplasm to the nucleus. Thus it diminishes the volume of cerebral infarction via delaying necrosis and ultimately act as anti- inflammatory agent [57]. It has long been used in ischemic stroke patients due to its potential efficacy to cross BBB and potentially inhibit the Ca2+/calmodulin-dependent phosphodiesterase-1 and voltage-dependent $\mathrm{Na}+$ channels [58].

\section{Toxicity of Vinpocetein}

The effective dose of vinpocetine against ischemia has been reported as $(10 \mathrm{mg} / \mathrm{kg})$ via intraperitoneal injection [57]. It appears to be probably harmless and even no substantial destructive possessions were reported in a study of people with $\mathrm{AD}$ one year treatment at the dose of 60 mg per day. On contrary some of the side effects of vinpocetine include nausea, stomach pain, headache, nervousness, flushing of face and weakened immune system $[175,180]$.

\section{Huperzine A}

Huperzine A is extracted from Chinese herb named Huperzia serrate which is commonly known as club moss and has been used for centuries to treat the inflammation, swelling, strains and fever [35]. It also potentially improves the cognitive function by increasing ACh levels in the brain [59] due to an efficacy to act as a natural inhibitor of AChE [181]. Its neuro-protective mechanism of action is similar to donepezil and galantamine [182] but it parades effective penetration to the $\mathrm{BBB}$, higher oral bioavailability as well as longer duration of action [59]. Different strategies have been done to develop 
the alternative sources of huperzine A because it occurs in slow growing members of Huperziaceae. This includes Phlegmariurus aquarrosus in vitro tissue culture [183] and extraction from endophytic fungi which is secluded from huperzine A manufacturing herb $[184,185]$.

\subsection{Therapeutic efficacy of huperzine $A$ in AD}

Huperzine A ameliorates the pathogenesis of AD through its neuro-protective property which majorly involves the mitochondrial protection from $A \beta$ aggregation induced toxicity. In vitro as well as in vivo studies revealed that it acts as an inhibitor of $A \beta$ and thus protects the mitochondrial damage to attenuate the oxidative stress [33]. The chronology of $A \beta$ induced neuron functional impairment is not utterly understood. However, a number of indications propose that $A \beta$ causes extra-synaptic space glutamate level elevation that consequences in ligand gated excitatory ion channels NMDARs overstimulation and finally leading to cell death as well as synaptic loss [186,187]. Huperzine A reduces the glutamate excite-toxicity via acting as NMDA receptor antagonist and minimize the level of synaptic loss along with neuronal cell death [188]. As the brain derived neurotropic factor (BDNF) is crucially important in memory and learning process, because it regulates synaptic plasticity, neuronal differentiation, axonal sprouting, as well as long-term potentiation (LTP) [189]. It has been revealed by voluminous number of studies that there is a reduced or diminished level of BDNF in patients with AD as well as with mild cognitive impairment (MCI) [189]. Huperzine A potentially exerts neuroprotection activity via signaling and promoting the production of BDNF and pro- BDNF to minimize the cognitive deficits and learning impairment induced by reduced level of BDNF [190]. Due to the potential neuroprotection possessions of huperzine A there is a need of further research to consider it as a drug for the treatment of $\mathrm{AD}$.

\section{Toxicity of Huperzine A}

Although huperzine A has been stated as a potential fighter of cognitive decline but it could be a lethal agent at high dose. Studies clarified its lethal dose as $>4 \mathrm{mg} / \mathrm{kg}$ of bodyweight and even $3 \mathrm{mg} / \mathrm{kg}$ for longer period like180 days in male rats whereas $1 \mathrm{mg} / \mathrm{kg}$ dose has been postulated as lethal for female rats as $2-4 \mathrm{mg} / \mathrm{kg}$ of bodyweight [191].

\section{Harmine}

Harmine is an indole $\beta$-carboline belonging to Nitrariaceae family which is isolated from Peganum harmala. It has a wide spectrum of pharmacological activities including antioxidant, antimicrobial, anti-inflammatory and neuro-protective properties [33]. It portrays neuro protective efficacy because of AChE, MAO-A and MAO-B [192] and tyrosinephosphorylation regulated kinase (DYRK1A) inhibition [61].

\subsection{Therapeutic efficacy of Harmine in AD}

AChE existence majorly contributes in the pathogenesis of $\mathrm{AD}$ which is more often associated with the formation of neurofibrillary tangles and $A \beta$ plaques [147]. Harmine has been reported to target the pathogenesis of $\mathrm{AD}$ because of its efficacy to potentially penetrate the $\mathrm{BBB}$, the parenchyma cells of brain as well as constrain the activity of AChE [193] which is the key enzyme involved in the metabolism and breakdown of a neurotransmitter known as ACh [194]. An experimental study suggested that harmine at the dose of $20 \mathrm{mg} / \mathrm{kg}$ could efficiently augment spatial cognition as well as amend compromised memory via cholinergic neurotransmission improvement [193]. Another pathological feature in $\mathrm{AD}$ is the aggregation and accumulation of tau proteins as well as the overexpression of brain proliferative agent named as tyrosinephosphorylation regulated kinase (DYRK1A) [195]. Harmine facilitates the brain development and proliferation via inhibiting the DYRK1A [61] as well as to significantly condense the tau protein phosphorylation via inhibiting the DYRK1Acatalyzed phosphorylation of tau. These findings suggested that harmine may have auspicious satisfying assistances in the treatment of AD [33].

\section{Toxicity of harmine}

Harmine tends to exhibit cytotoxic effects at certain doses in human skin keratinocytes. Experimental concentration of harmine and the percentage level of cytotoxicity in keratinocytes have been elucidated as 10, 30, 60 and $100 \mu \mathrm{g} / \mathrm{ml}$ cause $19.0,12.5,11.7$ and $11.0 \%$ cytotoxicity. It may interact with DNA topoisomerase due to the presence of methoxyl group and results in the cytotoxicity [196].

\section{8. (+)-erythravine and (+)-11-a-hydro- xyerythravine}

$(+)$-erythravine and (+)-11-a-hydroxyerythravine are the erythrine byproducts which are isolated from Erythrina mulungu flowers, commonly recognized as mulungu. It is chiefly found in several tropical regions and Brazilian cerrados [62]. Several parts including bark, fruits, seeds and flowers have been used to treat central nervous system (CNS) disorders and insomnia. It exerts anti-inflammatory 
effects, antinociceptive $[197,198]$, sedative, hypotonic, analgesic [62] and anticonvulsant effects [63].

\subsection{Therapeutic efficacy of (+)-erythravine and (+)-11-a-hydroxyerythravine in epilepsy}

Alterations in excitatory and inhibitory neurotransmitter pathways are major underlying mechanism involved in the onset as well as the conservation of epileptic seizures. Erythrine by products reduce the acetylcholine evoked currents by acting as an antagonist of neuronal nicotinic receptors [63]. Anticonvulsant possessions of (+)-erythravine and (+)-11-a-hydroxyerythravine have been reported to inhibit the seizures induced by phenyl tetrazole (PTZ), kainic acid and bicuculline, NMDA and kainic acid respectively. Both are efficiently absorbed in the GIT and also able to cross the BBB, which is crucially relevant to the advancement of new drugs directing the CNS, as well as anti- leptic drugs [62].

\section{Conclusion and future perspectives}

There are several drugs, which have been used for NDDs till date, but they do not possess the efficacy to amend the disease progression, rather they exert copious side effects. Frequent disease amending strategies have been discovered in the recent years and numerous compounds are being explored under these strategies but none of them have successfully grasped the market. In this perspective, plant grounded drugs have also developed as an innovative acumen. Numerous natural alkaloids retain mounting effects in the treatment of several NDDs. Along with modulating neurotransmitter system, natural alkaloids also possess anti-amyloid, antiinflammatory, and antioxidant properties as well as anti-depressive and anti-convulsing efficacy. Thus, natural alkaloids possess multiple mechanistic approaches in the treatment of NDDs. Alkaloids exert vast neuroprotective actions, but studies are needed on their toxic effects. There are few alkaloids which have been published with their toxic effects. Although many of the alkaloids with their adverse effects need to be reported. It has been suggested that the selection of natural alkaloids in the treatment of NDDs is safe as compared to synthetic drug. Numerous alkaloids and their derivatives have marvelous scope in the treatment of NDDs. But only few of them have prevalent clinical use. There is a vital requirement to design clinical trials for such compounds that are not even entered in the clinical trials till date, because the natural alkaloids are encouraging hope in slowing the development and progression of NDDs.

\section{Acknowledgement}

This study was supported by the Ministry of
Science and Technology (2016YFE0128500), Jilin Provincial Science \& Technology Department (20170204009YY, 20150101187JC, 20150414007GH), Changchun Science \& Technology Department (17YJ006, 17YJ001), Jilin Province Development and Reform Commission (2016C047-3, 2016C048-3), Jilin Province Education Department (2015-526, 2015-551), University S \& T Innovation Platform of Jilin Province for Economic Fungi (\#2014B-1). National Natural Science Foundation of China (No. 30871301, 30700827), and the Program for Introducing Talents to Universities (No. B07017).

\section{Competing Interests}

The authors have declared that no competing interest exists.

\section{References}

1. Kovacs GG. CURRENT CONCEPTS OF NEURODEGENERATIVE DISEASES. Cit EMJ Neurol. 2014;1(July):78-86.

2. Van Assche R, Temmerman L, Dias DA, Boughton B, Boonen K, Braeckman $\mathrm{BP}$, et al. Metabolic profiling of a transgenic Caenorhabditis elegans Alzheimer model. Metabolomics. 2015;11(2):477-86

3. Hussain G, Shahzad A, Anwar H, Sohail MU, Baig SM, Shabbir A, et al. Neurological disorder burden in Faisalabad, Punjab-Pakistan: data from the major tertiary care centers of the city. Pakistan J Neurol Sci. 2017;12(3).

4. Kumar Gp, Khanum F. Neuroprotective potential of phytochemicals. Pharmacogn Rev [Internet]. 2012;6(12):81. Available from: http://www.phcogrev.com/text.asp?2012/6/12/81/99898

5. Hussain G, Schmitt F, Henriques A, Lequeu T, Rene F, Bindler F, et al. Systemic down-regulation of delta-9 desaturase promotes muscle oxidative metabolism and accelerates muscle function recovery following nerve injury. PLoS One [Internet]. 2013;8(6):e64525. Available from: http://www.pubmedcentral.nih.gov/articlerender.fcgi?artid=3681796\&tool= pmcentrez\&rendertype $=$ abstract

6. Hussain G, Schmitt F, Loeffler J-P, Gonzalez de Aguilar J-L. Fatting the brain: a brief of recent research. Front Cell Neurosci [Internet]. 2013;7(September):144. Available

from: http://www.pubmedcentral.nih.gov/articlerender.fcgi?artid=3766822\&tool= pmcentrez\&rendertype $=$ abstract

7. Schmitt F, Hussain G, Dupuis L, Loeffler J-P, Henriques A. A plural role for lipids in motor neuron diseases: energy, signaling and structure. Front Cell Neurosci [Internet]. 2014;8(February):25. Available from: http://journal.frontiersin.org/article/10.3389/fncel.2014.00025/abstract

8. Cai Z, Wang C, Yang W. Role of berberine in Alzheimer's disease Neuropsychiatric Disease and Treatment. 2016. 12: 2509-20.

9. Kwon J, Seo YH, Lee JE, Seo EK, Li S, Guo Y, et al. Spiroindole Alkaloids and Spiroditerpenoids from Aspergillus duricaulis and Their Potential Neuroprotective Effects. J Nat Prod. 2015;78(11):2572-9.

10. Nhan HS, Chiang K, Koo EH. The multifaceted nature of amyloid precursor protein and its proteolytic fragments: friends and foes. Acta Neuropathologica. 2015. 129:1-19.

11. Baranello RJ, Bharani KL, Padmaraju V, Chopra N, Lahiri DK, Greig NH, et al. Amyloid-Beta Protein Clearance and Degradation (ABCD) Pathways and their Role in Alzheimer's Disease. Curr Alzheimer Res. 2015;12:32-46.

12. Kamagata K, Tomiyama H, Hatano T, Motoi Y, Abe O, Shimoji K, et al. A preliminary diffusional kurtosis imaging study of Parkinson disease: Comparison with conventional diffusion tensor imaging. Neuroradiology. 2014;56(3):251-8

13. Schrag A, Horsfall L, Walters K, Noyce A, Petersen I. Prediagnostic presentations of Parkinson's disease in primary care: A case-control study. Lancet Neurol. 2015;14(1):57-64.

14. Palfi S, Gurruchaga JM, Ralph GS, Lepetit H, Lavisse S, Buttery PC, et al. Long-term safety and tolerability of ProSavin, a lentiviral vector-based gene therapy for Parkinson's disease: a dose escalation, open-label, phase 1/2 trial. Lancet. 2014;383(9923):1138-46.

15. McNamara CG, Tejero-Cantero Á, Trouche S, Campo-Urriza N, Dupret D. Dopaminergic neurons promote hippocampal reactivation and spatial memory persistence. Nat Neurosci. 2014;17(12):1658-60.

16. Recasens A, Dehay B. Alpha-synuclein spreading in Parkinsonâ $\mathfrak{\epsilon}^{\mathrm{TM}} \mathrm{S}$ disease. Front Neuroanat. 2014;8.

17. Schapira AH V, Olanow CW, Greenamyre JT, Bezard E. Slowing of neurodegeneration in Parkinson's disease and Huntington's disease: Future therapeutic perspectives. Lancet. 2014;384(9942):545-55. 
18. Bates GP, Dorsey R, Gusella JF, Hayden MR, Kay $C$, Leavitt BR, et al. Huntington disease. Vol. 1, Nature Reviews Disease Primers. 2015

19. Sepers MD, Raymond LA. Mechanisms of synaptic dysfunction and excitotoxicity in Huntington's disease. Drug Discovery Today. 2014. 19: 990-6.

20. Jiang W, Wei W, Gaertig MA, Li S, Li XJ. Therapeutic effect of berberine on Huntington's disease transgenic mouse model. PLoS One. 2015;10(7):1-16.

21. Martin DDO, Ladha S, Ehrnhoefer DE, Hayden MR. Autophagy in Huntington disease and huntingtin in autophagy. Trends Neurosci. 2015;38(1):26-35

22. Vieweg $\mathrm{S}$. The role of the polyglutamine and $\{\mathrm{N}\}$-terminal domains in regulating the aggregation and structural properties of $\{\mathrm{H}\}$ untingtin $\{\mathrm{E}\}$ xon 1. [Lausanne]: EPFL; 2017.

23. Rawlins MD, Wexler NS, Wexler AR, Tabrizi SJ, Douglas I, Evans SJW, et al. The prevalence of huntington's disease. Vol. 46, Neuroepidemiology. 2016: 144-53.

24. Kopyta I, Zimny M. Significant risk factors in the etiology of arterial ischemic stroke in children. CNS J. 2015;1(1):6-13.

25. Guo Y, Li P, Guo Q, Shang K, Yan D, Du S, et al. Pathophysiology and Biomarkers in Acute Ischemic Stroke - A Review. Trop J Pharm Res [Internet]. 2014;12(6):1097. Available http://www ajolinfo/index.php/tipr/article/view/99924

26. Powers WJ, Derdeyn CP, Biller J, Coffey CS, Hoh BL, Jauch EC, et al. 2015 AHA/ASA Focused Update of the 2013 Guidelines for the Early Management of Patients With Acute Ischemic Stroke Regarding Endovascular Treatment. Stroke. 2015. STR.0000000000000074.

27. Salinet ASM, Panerai RB, Robinson TG. The longitudinal evolution of cerebral blood flow regulation after acute ischaemic stroke. Cerebrovasc Dis Extra. 2014;4(2):186-97.

28. Wang Y, Reis C, Applegate R, Stier G, Martin R, Zhang JH. Ischemic conditioning-induced endogenous brain protection: Applications pre-, per- or post-stroke. Vol. 272, Experimental neurology. 2015: 26-40.

29. Adilijiang A, Guan T, He J, Hartle K, Wang W, Li X. The protective effects of areca catechu extract on cognition and social interaction deficits in a cuprizone-induced demyelination model. Evidence-based Complement Altern Med. 2015;2015.

30. Rački V, Petrić D, Kučić N, Gržeta N, Jurdana K, Rončević-Gržeta I. Cortical gray matter loss in schizophrenia: Could microglia be the culprit? Med Hypotheses. 2016;88:18-21.

31. Kahn RS, Sommer IE, Murray RM, Meyer-Lindenberg A, Weinberger DR, Cannon TD, et al. Schizophrenia. Nat Rev Dis Prim. 2015;1.

32. Snyder MA, Gao W-J. NMDA hypofunction as a convergence point for progression and symptoms of schizophrenia. Front Cell Neurosci. 2013;7.

33. Choudhury B, Saytode P, Shah V. NEURODEGENRATIVE DISORDERS: PAST, PRESENT AND FUTURE. Int J Appl Pharm Biotechnol. 2014;5(2):14-28.

34. Girdhar S, Girdhar A, Verma SK, Lather V, Pandita D. Plant derived alkaloids in major neurodegenerative diseases: from animal models to clinical trials. J Ayurvedic Herb Med. 2015;1(3):91-100.

35. Cushnie TPT, Cushnie B, Lamb AJ. Alkaloids: An overview of their antibacterial, antibiotic-enhancing and antivirulence activities. Vol. 44, International Journal of Antimicrobial Agents. Elsevier B.V.; 2014: 377-86.

36. Ng YP, Or TCT, Ip NY. Plant alkaloids as drug leads for Alzheimer's disease. Neurochem Int. 2015 Oct:89:260-70.

37. Amirkia V, Heinrich M. Alkaloids as drug leads - A predictive structural and biodiversity-based analysis. Phytochem Lett. 2014;10:xlviii-liiii.

38. Abhijit Dey AM. Plant-Derived Alkaloids: A Promising Window for Neuroprotective Drug Discovery. In: Discovery and Development of Neuroprotective Agents from Natural Products. 2017: 237-320.

39. Cortes N, Posada-Duque RA, Alvarez R, Alzate F, Berkov S, Cardona-Gómez GP, et al. Neuroprotective activity and acetylcholinesterase inhibition of five Amaryllidaceae species: A comparative study. Life Sci. 2015;122:42-50.

40. Imenshahidi M, Qaredashi R, Hashemzaei M, Hosseinzadeh H. Inhibitory effect of Berberis vulgaris aqueous extract on acquisition and reinstatement effects of morphine in conditioned place preferences (CPP) in mice. Jundishapur J Nat Pharm Prod. 2014;9(3).

41. Jin Y, Khadka DB, Cho W-J. Pharmacological effects of berberine and its derivatives: a patent update. Expert Opin Ther Pat. 2016;26(2):229-43.

42. Jiang $\mathrm{WX}, \mathrm{Li} \mathrm{SH}, \mathrm{Li} \mathrm{XJ}$. Therapeutic potential of berberine against neurodegenerative diseases. Vol. 58, Science China Life Sciences. 2015: 564-9.

43. Jiang W, Wei W, Gaertig MA, Li S, Li XJ. Therapeutic effect of berberine on Huntington's disease transgenic mouse model. PLoS One. 2015;10(7).

44. Mojarad TB, Roghani M. The anticonvulsant and antioxidant effects of berberine in kainate-induced temporal lobe epilepsy in rats. Basic Clin Neurosci. 2014;5(2):124-30.

45. Zhu HL, Wan JB, Wang YT, Li BC, Xiang C, He J, et al. Medicinal compounds with antiepileptic/anticonvulsant activities. Vol. 55, Epilepsia. 2014: 3-16.

46. Acqua SD. Plant-derived acetylcholinesterase inhibitory alkaloids for the treatment of Alzheimer's disease. Bot Targets Ther. 2013;3:19-28.

47. Kumar A, Singh A, Ekavali. A review on Alzheimer's disease pathophysiology and its management: An update. Vol. 67, Pharmacological Reports. 2015: 195-203.

48. Mikkilineni S, Cantuti-Castelvetri I, Cahill CM, Balliedier A, Greig NH, Rogers JT. The anticholinesterase phenserine and its enantiomer posiphen as 5'untranslated-region-directed translation blockers of the Parkinson's alpha synuclein expression. Parkinsons Dis. 2012;2012:5-8.
49. Mishra A, Punia JK, Bladen C, Zamponi GW, Goel RK. Anticonvulsant mechanisms of piperine, a piperidine alkaloid. Channels. 2015;9(5):317-23.

50. Hritcu L, Noumedem JA, Cioanca O, Hancianu M, Kuete V, Mihasan M. Methanolic Extract of Piper nigrum Fruits Improves Memory Impairment by Decreasing Brain Oxidative Stress in Amyloid Beta(1-42) Rat Model of Alzheimer's Disease. Cell Mol Neurobiol. 2014;34(3):437-449.

51. Al-Baghdadi OB, Prater NI, Van Der Schyf CJ, Geldenhuys WJ. Inhibition of monoamine oxidase by derivatives of piperine, an alkaloid from the pepper plant Piper nigrum, for possible use in Parkinson's disease. Bioorganic Med Chem Lett. 2012;22(23):7183-8.

52. Carradori S, Ascenzio MD, Chimenti P, Secci D, Bolasco A. Selective MAO-B inhibitors : a lesson from natural products. Mol Divers. 2014;18:219-43.

53. Dimatelis JJ, Russell VA, Stein DJ, Daniels WM. The effects of lobeline and naltrexone on methamphetamine-induced place preference and striatal dopamine and serotonin levels in adolescent rats with a history of maternal separation. Vol. 27, Metabolic Brain Disease. 2012: 351-61.

54. Xiao F, Yan B, Chen L, Zhou D. Review of the use of botanicals for epilepsy in complementary medical systems - Traditional Chinese Medicine. Vol. 52, Epilepsy and Behavior. 2015: 281-9.

55. Grizzell JA, Patel S, Barreto GE, Echeverria V. Cotinine improves visual recognition memory and decreases cortical Tau phosphorylation in the Tg6799 mice. Prog Neuro-Psychopharmacology Biol Psychiatry. 2017;78:75-81.

56. Liu Y-J, Peng W, Hu M-B, Xu M, Wu C-J. The pharmacology, toxicology and potential applications of arecoline: a review. Pharm Biol. 2016:54(11):2753-60.

57. Rivera-Oliver M, Díaz-Ríos M. Using caffeine and other adenosine receptor antagonists and agonists as therapeutic tools against neurodegenerative diseases: A review. Vol. 101, Life Sciences. 2014: 1-9.

58. Wang H, Zhang K, Zhao L, Tang J, Gao L, Wei Z. Anti-inflammatory effects of vinpocetine on the functional expression of nuclear factor-kappa $B$ and tumor necrosis factor-alpha in a rat model of cerebral ischemia-reperfusion injury. Neurosci Lett. 2014;566:247-51.

59. Zhang F, Yan C, Wei C, Yao Y, Ma X, Gong Z, et al. Vinpocetine Inhibits NF-KB-Dependent Inflammation in Acute Ischemic Stroke Patients. Transl Stroke Res. 2017;

60. Xing S, Zhu C, Zhang R, An L. Huperzine A in the Treatment of Alzheimer's Disease and Vascular Dementia: A Meta-Analysis. Evidence-Based Complement Altern Med. 2014;2014:1-10.

61. Yadav M, Parle M, Sharma N, Ghimire K, Khare N. Role of Bioactive Phytoconstituents from Several Traditional Herbs as Natural Neuroprotective Agents Role of Bioactive Phytoconstituents from Several Traditional Herbs as Natural Neuroprotective Agents. 2016;(August).

62. Dakic $\mathrm{V}$, Maciel $\mathrm{R}$ de $\mathrm{M}$, Drummond $\mathrm{H}$, Nascimento JM, Trindade $\mathrm{P}$, Rehen SK. Harmine stimulates proliferation of human neural progenitors. PeerJ. 2016;4:e2727.

63. Faggion SA, Cunha AOS, Fachim HA, Gavin AS, dos Santos WF, Pereira AMS, et al. Anticonvulsant profile of the alkaloids (+)-erythravine and (+)-11-a-hydroxy-erythravine isolated from the flowers of Erythrina mulungu Mart ex Benth (Leguminosae-Papilionaceae). Epilepsy Behav. 2011;20(3):441-6

64. Setti-Perdigão P, Serrano MAR, Flausino OA, Bolzani VS, Guimarães MZP, Castro NG. Erythrina mulungu alkaloids are potent inhibitors of neuronal nicotinic receptor currents in mammalian cells. PLoS One. 2013;8(12):8-13.

65. Patil S, Tawari S, Mundhada D, Nadeem S. Protective effect of berberine, an isoquinoline alkaloid ameliorates ethanol-induced oxidative stress and memory dysfunction in rats. Pharmacol Biochem Behav. 2015;136:13-20.

66. Han AM, Heo H, Kwon YK. Berberine Promotes Axonal Regeneration in Injured Nerves of the Peripheral Nervous System. J Med Food [Internet]. 2012;15(4):413-7. Available http://online.liebertpub.com/doi/abs/10.1089/jmf.2011.2029

67. Yan R, Vassar R. Targeting the $\beta$ secretase BACE1 for Alzheimer's disease therapy. Vol. 13, The Lancet Neurology. 2014: 319-29.

68. Panahi N, Mahmoudian M, Mortazavi P, Hashjin GS. Effects of berberine on beta-secretase activity in a rabbit model of Alzheimer's disease. Arch Med Sci $\begin{array}{llll}\text { [Internet]. 2013;9(1):146-50. Available } & \text { from: }\end{array}$ http://www.ncbi.nlm.nih.gov/pubmed/23516061

69. Mathew B, Suresh J, Mathew GE, Parasuraman R, Abdulla N. Plant secondary metabolites- potent inhibitors of monoamine oxidase isoforms. Cent Nerv Syst Agents Med Chem. 2014;14(1):28-33.

70. Pohanka M. Inhibitors of acetylcholinesterase and butyrylcholinesterase meet immunity. Vol. 15, International Journal of Molecular Sciences. 2014: 9809-25.

71. Huang M, Jiang X, Liang Y, Liu Q, Chen S, Guo Y. Berberine improves cognitive impairment by promoting autophagic clearance and inhibiting production of $\beta$-amyloid in APP/tau/PS1 mouse model of Alzheimer's disease. Exp Gerontol. 2017;91:25-33.

72. Kim M, Cho KIHO, Shin MS, Lee JM, Cho HS, Kim CJU, et al. Berberine prevents nigrostriatal dopaminergic neuronal loss and suppresses hippocampal apoptosis in mice with Parkinson's disease. Int J Mol Med. 2014;33(4):870-8

73. Zhang $\mathrm{Q}$, Bian $\mathrm{H}$, Guo $\mathrm{L}$, Zhu H. Pharmacologic preconditioning with berberine attenuating ischemia-induced apoptosis and promoting autophagy in neuron. Am J Transl Res. 2016;8(2):1197-207.

74. Ciechanover A, Kwon YT. Degradation of misfolded proteins in neurodegenerative diseases: therapeutic targets and strategies. Exp Mol Med. 2015;47(3):e147. 
75. Parsons MP, Raymond LA. Extrasynaptic NMDA receptor involvement in central nervous system disorders. Neuron. 2014;82(2):279-93.

76. Chen C, Yu Z, Li Y, Fichna J, Storr M. Effects of Berberine in the Gastrointestinal Tract - A Review of Actions and Therapeutic Implications. Am J Chin Med. 2014;42(5):1053-70.

77. Godugu C, Patel AR, Doddapaneni R, Somagoni J, Singh M. Approaches to improve the oral bioavailability and effects of novel anticancer drugs berberine and betulinic acid. PLoS One. 2014;9(3).

78. Pang B, Zhao L, Zhou Q, Zhao T, Wang H, Gu C, et al. Review Article Application of Berberine on Treating Type 2 Diabetes Mellitus. Int J Endocrinol. 2015;2015.

79. Kaur R, Arora S. Alkaloids- Important Therapeutic Secondary Metabolites Of Plant Origin. J Crit Rev. 2015;2(3):1-8

80. Ye D, Bu H, Guo G, Shu B, Wang W, Guan X, et al. Activation of CXCL10/CXCR3 signaling attenuates morphine analgesia: Involvement of Gi protein. J Mol Neurosci. 2014;53(4):571-9.

81. Cui J, Wang Y, Dong Q, Wu S, Xiao X, Hu J, et al. Morphine Protects against Intracellular Amyloid Toxicity by Inducing Estradiol Release and Upregulation of Hsp70. J Neurosci [Internet]. 2011;31(45):16227-40. Available from: http://www.jneurosci.org/cgi/doi/10.1523/JNEUROSCI.3915-11.2011

82. Almeida MB, Costa-Malaquias A, Nascimento JLM, Oliveira KR, Herculano AM, Crespo-López ME. Therapeutic concentration of morphine reduces oxidative stress in glioma cell line. Brazilian J Med Biol Res. 2014;47(5):398-402.

83. Wang Y, Wang YX, Liu T, Law PY, Loh HH, Qiu Y, et al. $\mu$-Opioid Receptor Attenuates $A \beta$ Oligomers-Induced Neurotoxicity Through mTOR Signaling. CNS Neurosci Ther. 2015;21(1):8-14.

84. Berger JS, Gonzalez A, Hopkins A, Alshaeri T, Jeon D, Wang S, et al. Dose-response of intrathecal morphine when administered with intravenous ketorolac for post-cesarean analgesia: a two-center, prospective, randomized, blinded trial. In: International Journal of Obstetric Anesthesia. 2016: 3-11.

85. Ding X, Jin S, Niu X, Wang T, Zhao X, Ren H, et al. Morphine with adjuvant ketamine versus higher dose of morphine alone for acute pain: A meta-analysis. Int J Clin Exp Med. 2014;7(9):2504-10.

86. Ghafari S, Golalipour MJ. Prenatal morphine exposure reduces pyramidal neurons in CA1, CA2 and CA3 subfields of mice hippocampus. Iran J Basic Med Sci. 2014;17(3):155-61.

87. Moraga F, Hormazábal E, Venthur H, Quiroz A, Mutis A. REVIEW ARTICLE ALKALOID DISCOVERY AS NATURAL ACETYLCHOLINESTERASE INHIBITORS , FROM NATURE TO MOLECULAR DOCKING . Rev Farm Chile. 2016;9(56):16-25

88. de Andrade JP, Giordani RB, Torras-Claveria L, Pigni NB, Berkov S, Font-Bardia $\mathrm{M}$, et al. The Brazilian Amaryllidaceae as a source of acetylcholinesterase inhibitory alkaloids. Phytochem Rev. 2016;15(1):147-60.

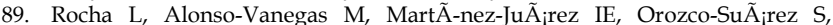
Escalante-Santiago D, Feria-Romero IA, et al. GABAergic Alterations in Neocortex of Patients with Pharmacoresistant Temporal Lobe Epilepsy Can Explain the Comorbidity of Anxiety and Depression: The Potential Impact of Clinical Factors. Front Cell Neurosci. 2015;8.

90. Golechha M, Sarangal V, Bhatia J, Chaudhry U, Saluja D, Arya DS. Naringin ameliorates pentylenetetrazol-induced seizures and associated oxidative stress, inflammation, and cognitive impairment in rats: Possible mechanisms of neuroprotection. Epilepsy Behav. 2014;41:98-102.

91. Pagliosa LB, Monteiro SC, Silva KB, de Andrade JP, Dutilh J, Bastida J, et al. Effect of isoquinoline alkaloids from two Hippeastrum species on in vitro acetylcholinesterase activity. Phytomedicine. 2010;17(8-9):698-701.

92. Tundis R, Menichini F, Conforti F, Loizzo MR, Bonesi M, Statti G, et al. A potential role of alkaloid extracts from Salsola species (Chenopodiaceae) in the treatment of Alzheimer's disease. J Enzyme Inhib Med Chem. 2009;24(3):818-24

93. Orhan IE, Kucukboyaci N, Calis I, Cerón-Carrasco JP, den-Haan H, Peña-García J, et al. Acetylcholinesterase inhibitory assessment of isolated constituents from Salsola grandis Freitag, Vural \& Adıgüzel and molecular modeling studies on N-acetyltryptophan. Phytochem Lett. 2017;20:373-8.

94. H. Ferreira-Vieira T, M. Guimaraes I, R. Silva F, M. Ribeiro F. Alzheimer's disease: Targeting the Cholinergic System. Curr Neuropharmacol. 2016;14(1):101-15

95. Chen T-H, Chou M-C, Lai C-L, Wu S-J, Hsu C-L, Yang Y-H. Factors affecting therapeutic response to Rivastigmine in Alzheimer's disease patients in Taiwan. Kaohsiung J Med Sci. 2017;33(6):277-83

96. Kim JK, Park SU. Pharmacological aspects of galantamine for the treatment of Alzheimer's disease. Vol. 16, EXCLI Journal. 2017: 35-9.

97. Lombardo S, Maskos U. Role of the nicotinic acetylcholine receptor in Alzheimer's disease pathology and treatment. Neuropharmacology. 2015;96(PB):255-62.

98. Raskind MA, Peskind ER, Wessel T, Yuan W. Galantamine in AD: A 6-month randomized, placebo-controlled trial with a 6-month extension. The Galantamine USA-1 Study Group. Neurology. 2000 Jun;54(12):2261-8.

99. Fuentealba J, Saez-Orellana F. Neuroactive alkaloids that modulate the neuronal nicotinic receptor and provide neuroprotection in an Alzheimer???s disease model: The case of teline monspessulana. Neural Regen Res. 2014;9(21):1880-1.

100. Dineley KT, Pandya AA, Yakel JL. Nicotinic ACh receptors as therapeutic targets in CNS disorders. Vol. 36, Trends in Pharmacological Sciences. 2015: 96-108.
101. Nikiforuk A, Kos T, Potasiewicz A, Popik P. Positive allosteric modulation of alpha 7 nicotinic acetylcholine receptors enhances recognition memory and cognitive flexibility in rats. Eur Neuropsychopharmacol. 2015;25(8):1300-13.

102. Kita Y, Ago Y, Higashino K, Asada K, Takano E, Takuma K, et al. Galantamine promotes adult hippocampal neurogenesis via M1 muscarinic and a7 nicotinic receptors in mice. Int J Neuropsychopharmacol [Internet]. 2014;17(12):1957-68. Available

from: https://academic.oup.com/ijnp/article-lookup/doi/10.1017/S146114571400 0613

103. Abd El-Wahab AE, Ghareeb DA, Sarhan EEM, Abu-Serie MM, El Demellawy MA. In vitro biological assessment of berberis vulgaris and its active constituent, berberine: Antioxidants, anti-acetylcholinesterase, anti-diabetic and anticancer effects. BMC Complement Altern Med. 2013;13(1):218.

104. Castillo WO, Aristizabal-Pachon AF. Galantamine protects against beta amyloid peptide-induced DNA damage in a model for Alzheimer's disease. Vol. 12, Neural Regeneration Research. 2017: 916-7.

105. Bhattacharya S, Haertel C, Maelicke A, Montag D. Galantamine slows down plaque formation and behavioral decline in the 5XFAD mouse model of Alzheimer's disease. PLoS One. 2014;9(2).

106. Hager K, Baseman AS, Nye JS, Brashear HR, Han J, Sano M, et al. Effects of galantamine in a 2-year, randomized, placebo-controlled study in Alzheimer's disease. Neuropsychiatr Dis Treat. 2014;10:391-401.

107. Woo FY, Basri M, Masoumi HRF, Ahmad MB, Ismail M. Formulation optimization of galantamine hydrobromide loaded gel drug reservoirs in transdermal patch for Alzheimer's disease. Int J Nanomedicine. 2015;10:3879-86

108. Caramelli P, Laks J, Palmini ALF, Nitrini R, Chaves MLF, Forlenza OV, et al. Effects of galantamine and galantamine combined with nimodipine on cognitive speed and quality of life in mixed dementia: a 24-week, randomized, placebo-controlled exploratory trial (the REMIX study). Arq Neuropsiquiatr. 2014;72(6):411-7.

109. Lima JA, Costa TWR, Silva LL, Miranda ALP, Pinto AC. Antinociceptive and anti-inflammatory effects of a Geissospermum Vellosii stem bark fraction. An Acad Bras Cienc. 2016;88(1):237-48.

110. Sajkowska-Kozielewicz JJ, Kozielewicz P, Barnes NM, Wawer I, Paradowska K. Antioxidant, Cytotoxic, and Antiproliferative Activities and Total Polyphenol Contents of the Extracts of Geissospermum reticulatum Bark. Oxid Med Cell Longev. 2016;2016.

111. Reina M, Ruiz-Mesia W, López-Rodríguez M, Ruiz-Mesia L, González-Coloma A, Martínez-Díaz R. Indole alkaloids from Geissospermum reticulatum. J Nat Prod. 2012;75(5):928-34.

112. Vital MJS, Carneiro ALB, Rocha LF, das Neves Amorim RC, Camargo MRM, Pohlit AM. Chemical composition, ethnopharmacology and biological activity of Geissospermum Allemão species (Apocynaceae Juss.). Rev Fitos Eletrônica. 2015:8(2):137-46

113. Araújo JQ, Lima JA, Pinto ADC, De Alencastro RB, Albuquerque MG. Docking of the alkaloid geissospermine into acetylcholinesterase: A natural scaffold targeting the treatment of Alzheimer's disease. J Mol Model. 2011;17(6):1401-12

114. Shaikh S, Verma A, Siddiqui S, Ahmad SS, Rizvi SMD, Shakil S, et al. Current acetylcholinesterase-inhibitors: A neuroinformatics perspective. CNS Neurol Disord - Drug Targets. 2014;13(3):391-401.

115. Orhan G, Orhan I, Subutay-Oztekin N, Ak F, Sener B. Contemporary Anticholinesterase Pharmaceuticals of Natural Origin and Their Synthetic Analogues for the Treatment of Alzheimers Disease. Recent Pat CNS Drug Discov [Internet]. 2009;4(1):43-51. Available from: http:/ / www.eurekaselect.com/openurl/content.php?genre=article\&issn=157 $4-8898 \&$ volume $=4 \&$ issue $=1 \&$ spage $=43$

116. Mohamed LA, Keller JN, Kaddoumi A. Biochimica et Biophysica Acta Role of $P$-glycoprotein in mediating rivastigmine effect on amyloid- $\beta$ brain load and related pathology in Alzheimer â€TM $\mathrm{s}$ disease mouse model. BBA - Mol Basis Dis. 2016;1862(4):778-87.

117. Wiese AJ, Brosnan RJ, Barter LS. Effects of acetylcholinesterase inhibition on quality of recovery from isoflurane-induced anesthesia in horses. Am J Vet Res. 2014;75(3):223-30.

118. Tie H-T, Su G-Z, He K, Liang S-R, Yuan H-W, Mou J-H. Efficacy and safety of ondansetron in preventing postanesthesia shivering: a meta-analysis of randomized controlled trials. BMC Anesthesiol. 2014;14:12

119. Wenger E, McDermott R, Synder W. Cultivating communities of pratice a guide to managing knowledge. J Knowl Manag Pract. 2002;24(2):304.

120. Guo H, Zhang X, Cui Y, Deng W, Xu D, Han H, et al. Isorhynchophylline protects against pulmonary arterial hypertension and suppresses PASMCs proliferation. Biochem Biophys Res Commun. 2014;450(1):729-34.

121. Zhou JY, Zhou SW. Isorhynchophylline: A plant alkaloid with therapeutic potential for cardiovascular and central nervous system diseases. Vol. 83, Fitoterapia. 2012: 617-26.

122. Ho TY, Tang NY, Hsiang CY, Hsieh CL. Uncaria rhynchophylla and rhynchophylline improved kainic acid-induced epileptic seizures via IL-1 $\beta$ and brain-derived neurotrophic factor. Phytomedicine. 2014;21(6):893-900.

123. Tsuji M, Takeuchi T, Miyagawa K, Ishii D, Imai $T$, Takeda K, et al. Yokukansan, a traditional Japanese herbal medicine, alleviates the emotional abnormality induced by maladaptation to stress in mice. Phytomedicine. 2014;21(3):363-71.

124. WEN-JUAN HUANG, XIA ZHANG and W-WC. Role of oxidative stress in Alzheimer's disease. Biomed Rep. 2016;519-522. 
125. Xian YF, Lin ZX, Mao OQ, Ip SP, Su ZR, Lai XP. Protective effect of isorhynchophylline against $\beta$-amyloid-induced neurotoxicity in PC12 cells. Cell Mol Neurobiol. 2012;32(3):353-60.

126. Xian YF, Mao QQ, Wu JCY, Su ZR, Chen JN, Lai XP, et al. Isorhynchophylline treatment improves the amyloid- $\beta$-induced cognitive impairment in rats via inhibition of neuronal apoptosis and tau protein hyperphosphorylation. J Alzheimer's Dis. 2014;39(2):331-46.

127. Akl H, Vervloessem T, Kiviluoto S, Bittremieux M, Parys JB, De Smedt H, et al. A dual role for the anti-apoptotic Bcl-2 protein in cancer: Mitochondria versus endoplasmic reticulum. Vol. 1843, Biochimica et Biophysica Acta - Molecular Cell Research. 2014: 2240-52.

128. Cooper JM, Wiklander PBO, Nordin JZ, Al-Shawi R, Wood MJ, Vithlani M, et al. Systemic exosomal siRNA delivery reduced alpha-synuclein aggregates in brains of transgenic mice. Mov Disord. 2014;29(12):1476-85.

129. Zhang H, Bai L, He J, Zhong L, Duan X, Ouyang L, et al. Recent advances in discovery and development of natural products as source for anti-Parkinson's disease lead compounds. Eur J Med Chem. 2017;141:257-72.

130. Lu J-H, Tan J-Q, Durairajan SSK, Liu L-F, Zhang Z-H, Ma L, et al. Isorhynchophylline, a natural alkaloid, promotes the degradation of alpha-synuclein in neuronal cells via inducing autophagy. Autophagy. 2012:8(1):98-108.

131. Ghavami S, Shojaei S, Yeganeh B, Ande SR, Jangamreddy JR, Mehrpour M, et al. Autophagy and apoptosis dysfunction in neurodegenerative disorders. Prog Neurobiol. 2014;112:24-49.

132. Yeggoni DP, Rachamallu A, Kallubai M, Subramanyam R. Cytotoxicity and comparative binding mechanism of piperine with human serum albumin and a-1-acid glycoprotein. J Biomol Struct Dyn. 2015;33(6):1336-51.

133. Damanhouri ZA. A Review on Therapeutic Potential of Piper nigrum L. (Black Pepper): The King of Spices. Med Aromat Plants. 2014;3(3).

134. Vasavirama K, Upender M. Piperine: A valuable alkaloid from piper species. Vol. 6, International Journal of Pharmacy and Pharmaceutical Sciences. 2014: 34-8.

135. Goswami PK, Samant M, Srivastava RS. Snake venom, anti-snake venom \& potential of snake venom. Int J Pharm Pharm Sci. 2014;6(5):4-7.

136. Hirose S. Mutant GABAA receptor subunits in genetic (idiopathic) epilepsy. In: Genetics of Epilepsy. 2014: 55-85.

137. Murata K, Matsumura S, Yoshioka Y, Ueno Y, Matsuda H. Screening of $\beta$-secretase and acetylcholinesterase inhibitors from plant resources. J Nat Med. 2015;69(1):123-129.

138. Rinwa P, Kumar A. Quercetin along with piperine prevents cognitive dysfunction, oxidative stress and neuro-inflammation associated with mouse model of chronic unpredictable stress. Arch Pharm Res. 2017;40(10):1166-75.

139. Shrivastava P, Vaibhav K, Tabassum R, Khan A, Ishrat T, Khan MM, et al. Anti-apoptotic and Anti-inflammatory effect of Piperine on 6-OHDA induced Parkinson's Rat model. J Nutr Biochem. 2013;24(4):680-7.

140. Shailendra Wadhwa, Sarita Singhal SR. Bioavailability Enhancement by Piperine: A Review. Asian J Biomed Pharm Sci. 2014;1-8.

141. Li CY, Zhao LM, Shi XW, Zhang JD. Lobeline shows protective effects against MPTP-induced dopaminergic neuron death and attenuates behavior deficits in animalsz. Exp Ther Med. 2014;7(2):375-8.

142. Martin CA, Nuzzo PA, Ranseen JD, Kleven MS, Guenthner G, Williams Y, et al. Lobeline Effects on Cognitive Performance in Adult ADHD. J Atten Disord. 2013;

143. Angeles ML, Kapadia N, Harding W. Aporphine Alkaloids as Ligands for Serotonin Receptors. Med Chem (Los Angeles). 2016;6(4):241-9.

144. Steinlein OK. Calcium signaling and epilepsy. Vol. 357, Cell and Tissue Research. 2014: 385-93.

145. Ribeiro RA, Leite JR. Nantenine alkaloid presents anticonvulsant effect on two classical animal models. Phytomedicine. 2003;10(6-7):563-8.

146. Kharkwal G, Brami-Cherrier K, Lizardi-Ortiz JE, Nelson AB, Ramos M, Del Barrio D, et al. Parkinsonism Driven by Antipsychotics Originates from Dopaminergic Control of Striatal Cholinergic Interneurons. Neuron. 2016;91(1):67-78

147. Barreto G, Iarkov A, Moran V. Beneficial effects of nicotine, cotinine and its metabolites as potential agents for Parkinson's disease. Front Aging Neurosci [Internet]. 2014;1-13. Available from: http://www.ncbi.nlm.nih.gov/pmc/articles/PMC4288130/

148. Fargo K. Alzheimer's Association Report: 2014 Alzheimers disease facts and figures. Alzheimer's Dement. 2014;10(2).

149. Akaike A, Takada-Takatori Y, Kume T, Izumi Y. Mechanisms of neuroprotective effects of nicotine and acetylcholinesterase inhibitors: Role of a4 and $\alpha 7$ receptors in neuroprotection. In: Journal of Molecular Neuroscience. 2010: 211-6.

150. Kim BG, Jee ÆSW, Lee ÆSH, Sin ÆJS, Bae ÆCJ, Lee BC, et al. Nicotine Leads to Improvements in Behavioral Impairment and an Increase in the Nicotine Acetylcholine Receptor in Transgenic Mice. 2008;1783-8.

151. Levy DT, Cummings KM, Villanti AC, Niaura R, Abrams DB, Fong GT, et al. A framework for evaluating the public health impact of e-cigarettes and other vaporized nicotine products. Addiction. 2017;112(1):8-17.

152. Mayer B. How much nicotine kills a human? Tracing back the generally accepted lethal dose to dubious self-experiments in the nineteenth century. Archives of Toxicology. 2014;88(1):5-7.

153. Pelissier-Rota MA, Pelosi L, Meresse P, Jacquier-Sarlin MR. Nicotine-induced cellular stresses and autophagy in human cancer colon cells: A supportive effect on cell homeostasis via up-regulation of Cox-2 and $\mathrm{PGE}<\mathrm{inf}>2</$ inf $>$ production. Int J Biochem Cell Biol. 2015;65:239-56.

154. Bhat SK, Ashwin D, Sarpangala M. Contamination and Adulteration in Arecanut ( Areca Catechu L .) And Its Chewing Foms: The Less Focused Subject by Health Researchers. 2017;11(1):7-12.

155. Carruthers SP, Gurvich CT, Rossell SL. The muscarinic system, cognition and schizophrenia. Neurosci Biobehav Rev. 2015;55:393-402.

156. Coppola M, Mondola R. Potential action of betel alkaloids on positive and negative symptoms of schizophrenia: A review. Vol. 66, Nordic Journal of Psychiatry. 2012: 73-8.

157. Woo TUW. Neurobiology of schizophrenia onset. Curr Top Behav Neurosci. 2014;16:267-95.

158. Bales A, Peterson MJ, Ojha S, Upadhaya K, Adhikari B, Barrett B. Associations between betel nut (Areca catechu) and symptoms of schizophrenia among patients in Nepal: A longitudinal study. Psychiatry Res. 2009;169(3):203-11.

159. Thal DM, Sun B, Feng D, Nawaratne V, Leach K, Felder CC, et al. Crystal structures of the M1 and M4 muscarinic acetylcholine receptors. Nature. 2016;531(7594):335-40.

160. Crook JM, Tomaskovic-Crook E, Copolov DL, Dean B. Decreased muscarinic receptor binding in subjects with schizophrenia: a study of the human hippocampal formation. Biol Psychiatry. 2000;48(5):381-8.

161. Cotter D. Reduced Neuronal Size and Glial Cell Density in Area 9 of the Dorsolateral Prefrontal Cortex in Subjects with Major Depressive Disorder. Cereb Cortex. 2002;12(4):386-94.

162. Deng C, Huang X-F. Decreased density of muscarinic receptors in the superior temporal gyrusin schizophrenia. J Neurosci Res. 2005;81(6):883-90.

163. Peng W, Liu Y-J, Wu N, Sun T, He X-Y, Gao Y-X, et al. Areca catechu L. (Arecaceae): A review of its traditional uses, botany, phytochemistry, pharmacology and toxicology. J Ethnopharmacol. 2015;164(Supplement C):340-56.

164. Zhou J, Sun Q, Yang Z, Zhang J. The Hepatotoxicity and Testicular Toxicity Induced by Arecoline in Mice and Protective Effects of Vitamins C and E. Korean J Physiol Pharmacol. 2014;18(2):143.

165. Cheng S-J, Ko H-H, Cheng S-L, Lee J-J, Chen H-M, Chang H-H, et al. Arecoline-stimulated placenta growth factor production in gingival epithelial cells: modulation by curcumin. Oral Dis. 2013;19(5):513-8

166. Ullah M, Cox S, Kelly E, Boadle R, Zoellner H. Arecoline is cytotoxic for human endothelial cells. J Oral Pathol Med. 2014;43(10):761-9.

167. McIntire LK, McKinley RA, Goodyear C, Nelson J. A comparison of the effects of transcranial direct current stimulation and caffeine on vigilance and cognitive performance during extended wakefulness. Brain Stimul. 2014;7(4):499-507.

168. Arendash GW, Mori T, Cao C, Mamcarz M, Runfeldt M, Dickson A, et al. Caffeine reverses cognitive impairment and decreases brain amyloid- $\beta$ levels in aged alzheimer's disease mice. J Alzheimer's Dis. 2009:17(3):661-80.

169. Collin L, Bohrmann B, Göpfert U, Oroszlan-Szovik K, Ozmen L, Grüninger F. Neuronal uptake of tau/pS422 antibody and reduced progression of tau pathology in a mouse model of Alzheimer's disease. Brain. 2014;137(10):2834-46.

170. Laurent C, Eddarkaoui S, Derisbourg M, Leboucher A, Demeyer D, Carrier S, et al. Beneficial effects of caffeine in a transgenic model of Alzheimer's disease-like tau pathology. Neurobiol Aging. 2014;35(9):2079-90.

171. Nehlig A. Effects of coffee/caffeine on brain health and disease: What should I tell my patients? Pract Neurol. 2016;16(2):89-95.

172. Ritchie K, Carrière I, de Mendonça A, Portet F, Dartigues JF, Rouaud O, et al. The neuroprotective effects of caffeine: a prospective population study (the Three City Study). Neurology. 2017;23:272-90.

173. More SV, Kumar H, Kim IS, Song SY, Choi DK. Cellular and molecular mediators of neuroinflammation in the pathogenesis of Parkinson's disease. Vol. 2013, Mediators of Inflammation. 2013.

174. Rivera-oliver M, Manuel D, Díaz-ríos M. Address for correspondence : NU SC. Life Sci. 2014;

175. Li X, Li W, Liu G, Shen X, Tang Y. Association between cigarette smoking and Parkinson's disease: A meta-analysis. Arch Gerontol Geriatr. 2015;61(3):510-6.

176. Avula B, Chittiboyina AG, Sagi S, Wang YH, Wang M, Khan IA, et al. Identification and quantification of vinpocetine and picamilon in dietary supplements sold in the United States. Drug Test Anal. 2016;8(3-4):334-43.

177. Ruiz-Miyazawa KW, Zarpelon AC, Pinho-Ribeiro FA, Pav?o-De-Souza GF, Casagrande R, Verri WA. Vinpocetine reduces carrageenan-induced inflammatory hyperalgesia in mice by inhibiting oxidative stress, cytokine production and NF-?B activation in the paw and spinal cord. PLoS One. $2015 ; 10(3)$.

178. Wang J, Dong T, Zhang Y, Lu Z, Zhai K, Liu X. Effects of vinpocetine and ozagrel on behavioral recovery of rats after global brain ischemia. J Clin Neurosci. 2014;21(4):661-3.

179. Hoesel B, Schmid JA. The complexity of NF-KB signaling in inflammation and cancer. Mol Cancer. 2013;12(1):86.

180. Liu T, Zhang L, Joo D, Sun S-C. NF-kB signaling in inflammation. Signal Transduct Target Ther. 2017:2:17023.

181. National Toxicology Program. Chemical Information Review Document for Vinpocetine. 2013;(42971):260.

182. Ratia M, Giménez-Llort L, Camps P, Muñoz-Torrero D, Pérez B, Clos M V., et al. Huprine $X$ and huperzine a improve cognition and regulate some neurochemical processes related with Alzheimer's disease in triple transgenic mice (3xTg-AD). Neurodegener Dis. 2013;11(3):129-40. 
183. Yang G, Wang Y, Tian J, Liu J-P. Huperzine A for Alzheimer's disease: a systematic review and meta-analysis of randomized clinical trials. PLoS One [Internet]. 2013;8(9):e74916. Available from: http:/ / www.pubmedcentral.nih.gov/articlerender.fcgi?artid=3781107\&tool= pmcentrez\&rendertype $=$ abstract

184. Ma X, Gang DR. In vitro production of huperzine A, a promising drug candidate for Alzheimer's disease. Phytochemistry. 2008;69(10):2022-8

185. Yan R, Zhang Z, Wang Y, Yang H, Zeng Q, Zhu D. Efficient strategy for maintaining and enhancing the huperzine a production of Shiraia sp. Slf14 through inducer elicitation. J Ind Microbiol Biotechnol. 2014;41(7):1175-9.

186. Su J, Yang M. Huperzine A production by Paecilomyces tenuis YS-13, an endophytic fungus isolated from Huperzia serrata. Nat Prod Res. 2015;29(11):1035-41.

187. Anggono V, Tsai L, Götz J. Glutamate Receptors in Alzheimer's Disease: Mechanisms and Therapies. Neural Plast. 2016;2016:1-2.

188. Peters C, Sepúlveda FJ, Fernández-Pérez EJ, Peoples RW, Aguayo LG. The Level of NMDA Receptor in the Membrane Modulates Amyloid- $\beta$ Association and Perforation. J Alzheimer's Dis. 2016;53(1):197-207.

189. Shao Z-Q. Comparison of the efficacy of four cholinesterase inhibitors in combination with memantine for the treatment of Alzheimer's disease. Int J Clin Exp Med. 2015;8(2):2944-8.

190. Budni J, Bellettini-santos T, Mina F, Garcez ML. The involvement of BDNF, NGF and GDNF in aging and Alzheimer â€TM $s$ disease. 2016;6(5):331-41.

191. Mao XY, Cao DF, Li X, Yin JY, Wang Z Bin, Zhang Y, et al. Huperzine a ameliorates cognitive deficits in streptozotocin-induced diabetic rats. Int J Mol Sci. 2014;15(5):7667-83

192. Ma T, Gong K, Yan Y, Zhang L, Tang P, Zhang X, et al. Huperzine A promotes hippocampal neurogenesis in vitro and in vivo. Brain Res. 2013;1506:35-43.

193. Klein-Junior L, Santos Passos C, Moraes A, Wakui V, Konrath E, Nurisso A, et al. Indole Alkaloids and Semisynthetic Indole Derivatives as Multifunctional Scaffolds Aiming the Inhibition of Enzymes Related to Neurodegenerative Diseases - A Focus on Psychotria L. Genus. Curr Top Med Chem. 2014;14(8):1056-75

194. He D, Wu H, Wei Y, Liu W, Huang F, Shi H, et al. Effects of harmine, an acetylcholinesterase inhibitor, on spatial learning and memory of APP/PS1 transgenic mice and scopolamine-induced memory impairment mice. Eur J Pharmacol. 2015;768:96-107.

195. Konrath EL, Passos CDS, Klein-Júnior LC, Henriques AT. Alkaloids as a source of potential anticholinesterase inhibitors for the treatment of Alzheimer's disease. J Pharm Pharmacol. 2013;65(12):1701-25.

196. Qian W, Jin N, Shi J, Yin X, Jin X, Wang S, et al. Dual-specificity tyrosine phosphorylation-regulated kinase 1A (Dyrk1A) enhances tau expression. J Alzheimer's Dis. 2013;37(3):529-38.

197. Chinwala Y, Bax L, Gallego A, Krishna K, Wright W. under the supervision of. 2016;

198. Vasconcelos SMM, Sales GTM, Lima N, Lobato R de FG, Macêdo DS, Barbosa-Filho JM, et al. Anti-inflammatory activities of the hydroalcoholic extracts from Erythrina velutina and E. Mulungu in mice. Brazilian J Pharmacogn. 2011;21(6):1155-8.

199. de Oliveira MSG, Aquino AB, da Silva DL, Aquino PG V, Santos MS, Porfírio APR, et al. Antinociceptive and anti-infl ammatory activity of hydroalcoholic extracts and fractions from Erythrina mulungu. Brazilian J Pharmacogn. 2011;22(1):157-61 